المجلة الدولية للتراث و السياحة و الضيافة ـ تصدر ها كلية السياحة و الفنادق - جامعة الفيوم، المجلد (11)، العدد (1/2) سبتمبر 2017

المخاطر وسُبل النجاة خلال أيام النسيء الخمسة في مصر القديمة حتى نهاية العصرين

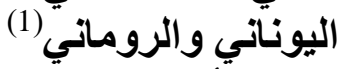

خلود عبد المنعم الجمال أيمن وزيري الرئي محمد أحمد السيد كلية الأثار، جامعة الفيوم

ملخص

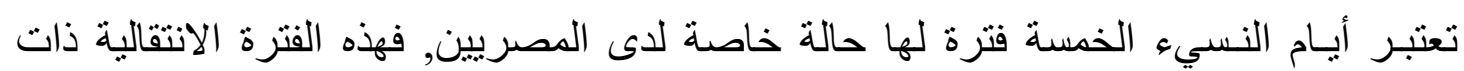
طبيعة متناقضة؛ تحمل الخير والثر في آن واحد، تقام فيها الاحتفالات وتقام فيها المذابح. وقدة التداء

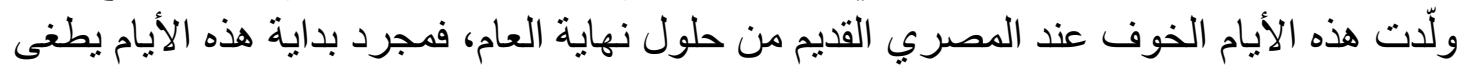
الخوف ويثار الرعب حتى تنتهي في سلام ويظهر فجر العام الجديد. الأهداف: يهدف البحث إلى إماطة اللثام عن المخاطر التي تكتنف أيام النسيء الخمسة في مصر فئر التهر

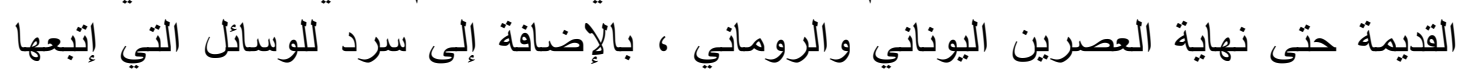
المصري القديم للنجاة من تللك المخاطر وفقاً للمصادر و المُعتقدات المصرية المية القديمة. الكلمات الدالة: أيام النسيء الخمسة، المخاطر، سُبل النجاة، رسل سخمت، مردة خاتيو، ولثة الأوشابتي، التمائم السحرية.

مقدمة

إتضح من خلال مفاهيم اندماج المعتقدات الدينية بالأساطير أنه تجلى ظهور القصص

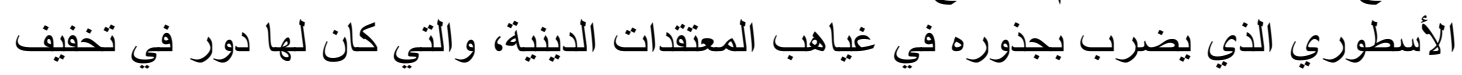

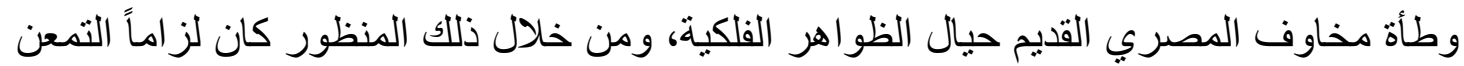
في تحليل وتفسير المعطيات و الثواهد التي كانت نتاجاً عن المصادر المصرية القديمة. وقد كان

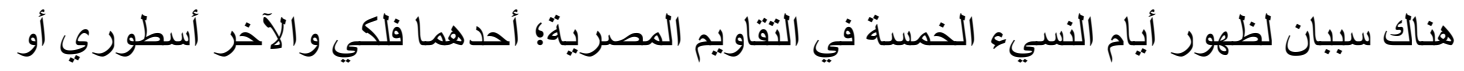

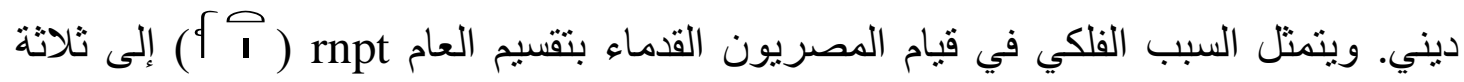

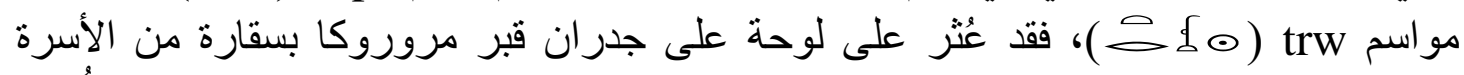

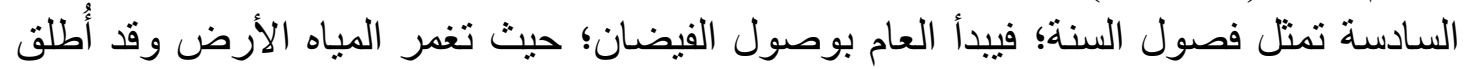

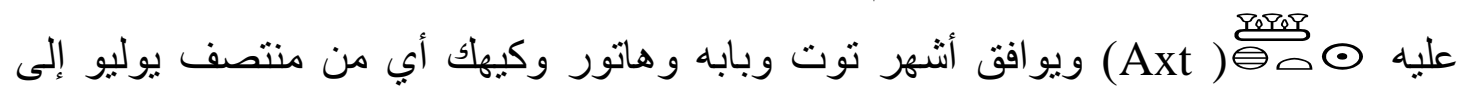
منتصف أكتوبر وقد رُمز لله بالعلامة الهيروغليفية قfro للالالة على أنه فصل الخير (2).

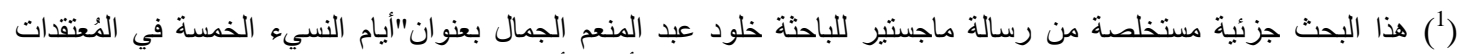

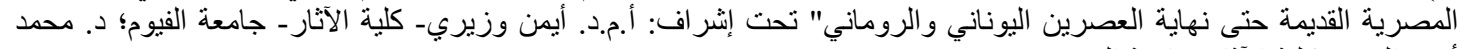

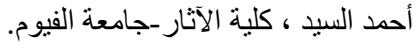


المجلة الدولية للتراث والسياحة والضيافة ـ تصدر ها كلية السياحة و الفنادق - جامعة الفيوم، المجلد (11)، العدد (1/2) سبتمبر كلية 2017

شكل 1: مشهد يوضح فصول السنة من مقبرة مرروكا بسقارة، نقلاً عن : وليم نظير, الثروة

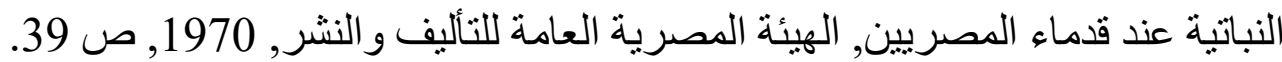

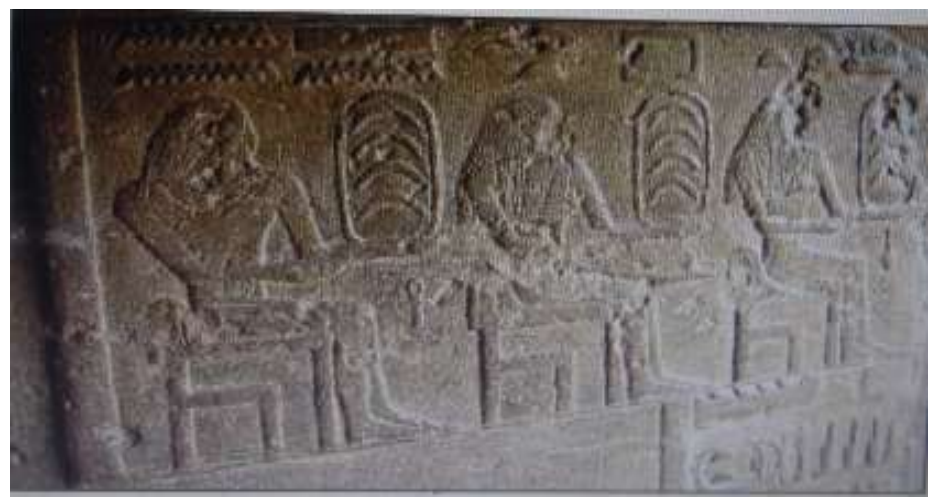

و أما الفصل الثاني هو فصل البذر وبدء الزر اعة ويتميز بظهور الأرض بعد انحسار مياه

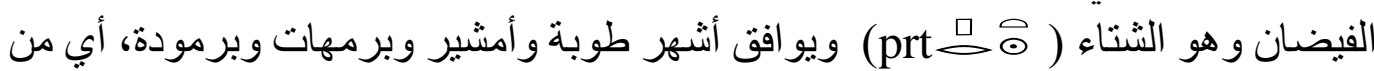

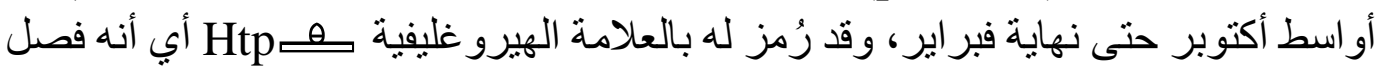

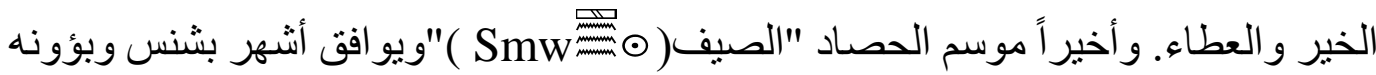
و أبيب ومسري أي من فبر اير حتي يونيو، ورُمز له بالعلامة الهيرو غليفية أبnx أبي أنه فصل الحياة

(1). شكل 2: مشهد يوضح أسماء الشهور في مصر القديمة، نقلاً عن : أحمد كمال, بُغية الطالبين

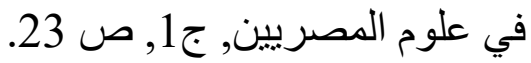

\begin{tabular}{|c|c|c|c|c|c|c|c|}
\hline & & & & & & & \\
\hline - & ewor T & 5101 & ט121 & , ou $>3$ & 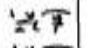 & Ttut & \\
\hline بالب & $\pi a \omega \pi 1$ & ransas & $x \cdot s>$ & $\Delta n=\infty>$ & $\% \pi$ & $\pi$ tife & \\
\hline هائور & $\omega \theta \omega \mathrm{r}$ & poll sm & $\Leftrightarrow 1>r$ & now $20-4$ & 光可 & int lift & 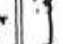 \\
\hline $4 \quad 5$ & xomk & 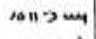 & UI sand & N"ISTm & \% ज्ञा & 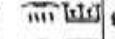 & r. \\
\hline طوبه & TCB & $z \lambda t$ & 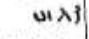 & 10.PIP3 & $n T$ & $T=$ & . \\
\hline اهيخ & MESIP & $2 \lambda>$ & $\omega \lambda \leftrightharpoons$ & 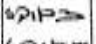 & เา & $\pi=$ & 4 त? \\
\hline بै: & parkno & & sixy & ositen & वान & iil $=0$ & \\
\hline : & papteor TI & $2 \lambda$ iny & Si & | & 1ता & in $=$ & $=1$ \\
\hline يشن & Taylome & $\| \lambda ?$ & $v>1$ & J $=\| 1 \mathrm{X} T$ & 3057 & $T$ 耐 & $1 \sqrt{-3}$ \\
\hline بؤث & racost & $1 \lambda 3$ & $2 A=$ & stil $x$ as & $3 \omega^{-1}$ & $\pi$ & $\frac{3}{3}$ \\
\hline ! & entr & $" x m$ & $v \lambda=1$ & gallinges & $3 \omega=$ & iㅔ 몰ㄹ & $+\frac{3}{3}$ \\
\hline ans & necorn & $111 \mathrm{Am}$ & $v \lambda m$ & $1 / 011 \times 104$ & $3 \infty \pi$ & 제 & $\varepsilon \|^{3}$ \\
\hline
\end{tabular}

وبالتالي فقد قسم المصري القديم كل موسم إلى أربعة أشهر( (Abd

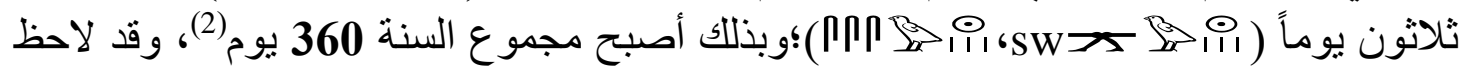
المصريون القدماء الفارق بينها وبين السنة الفعلية ولذلك أضافوا خمسة أيام فوق العام

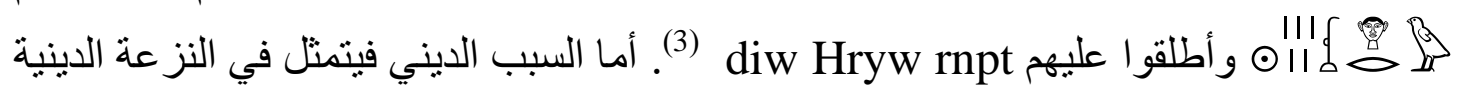

${ }^{2}$ ) (Gardiner 2010), p.107.

(') ( نظير1970)، ص 37.

$\left(^{3}\right)$ (White 1970), p.94; (Mahler 1911), p.87. للمزيد عن العام المصري القديم راجع:( وزيري 2006)، ص، 19-25 . 
المجلة الدولية للتراث و السياحة والضيافة ـ تصدر ها كلية السياحة و الفنادق - جامعة الفيوم، المجلد (11)، العدد (1/2) سبتمبر 2017

المعروفة عن القدماء المصريين والتي كانت السبب الرئيسي في ابتكار التقاويم المصرية القديمة

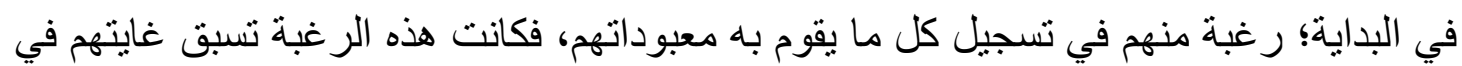

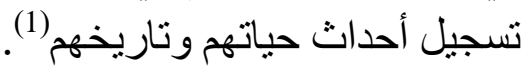

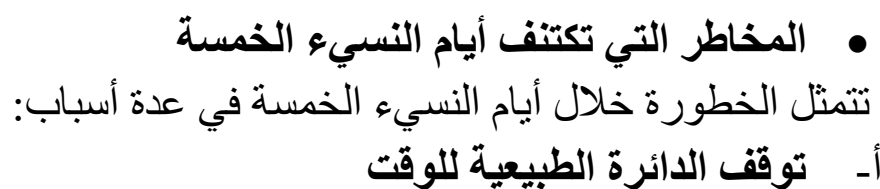

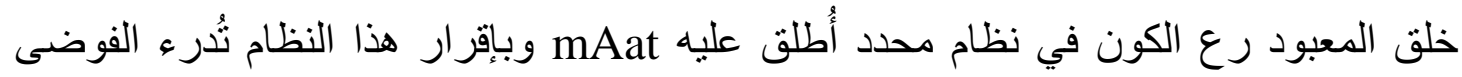

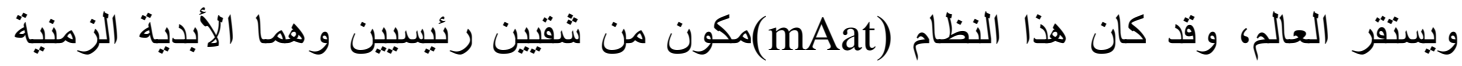

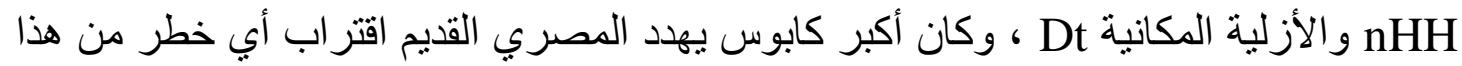

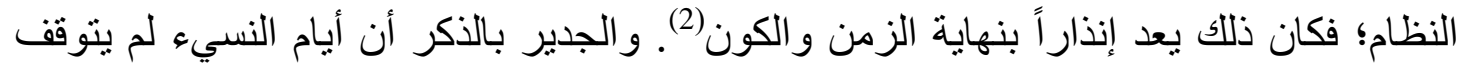

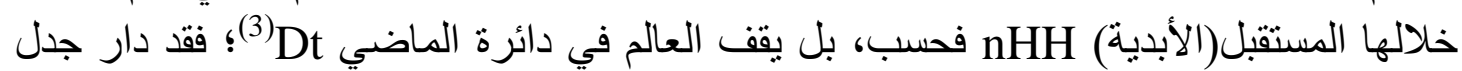

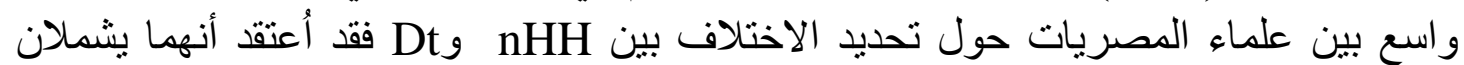

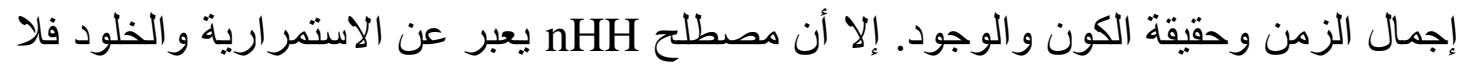

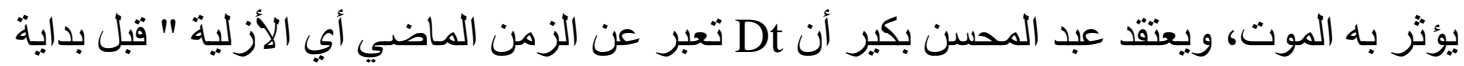

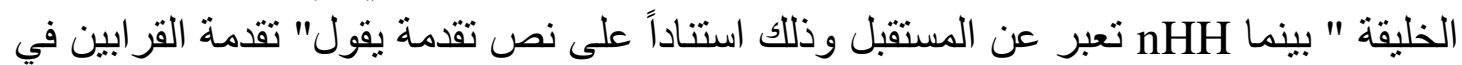

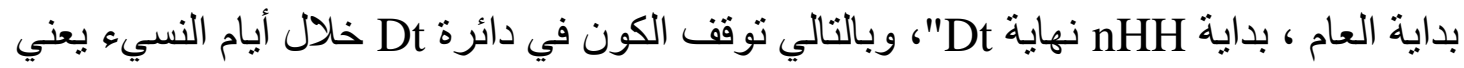

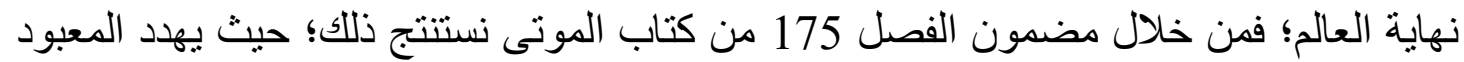

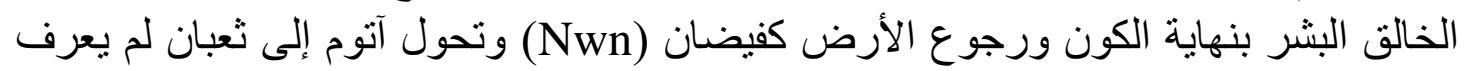

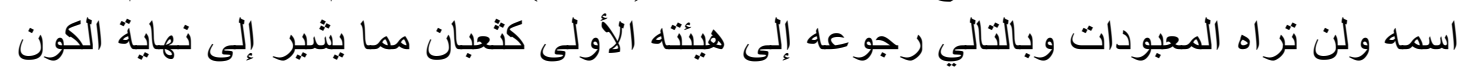

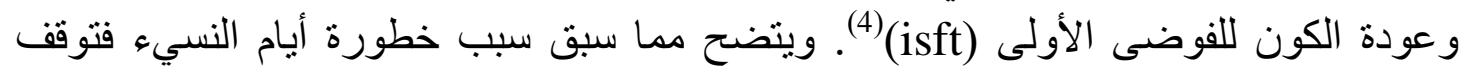

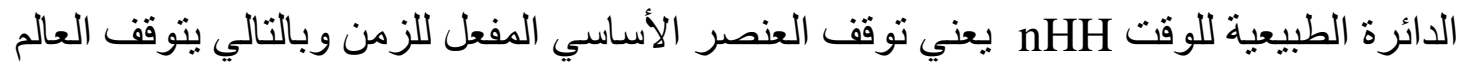

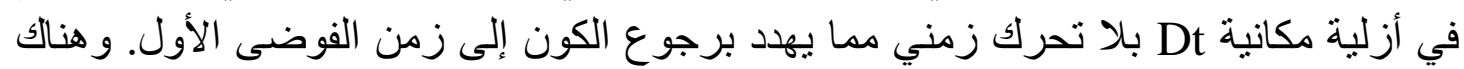

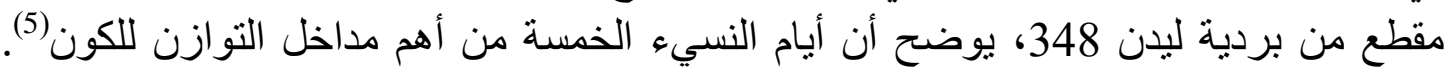

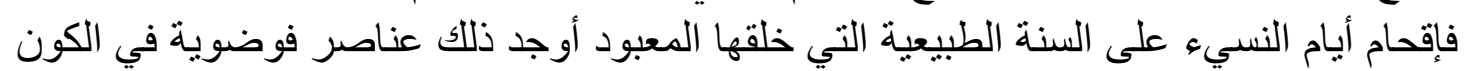

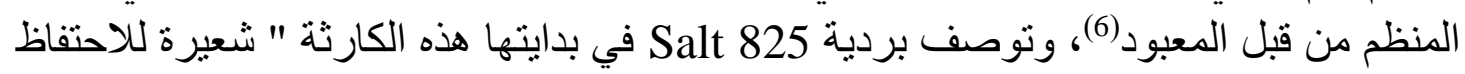
بالحياة في مصر "(7)؛ فأي تدخل في الثنائية الكونية (Dt،nHH) بمثابة إلغاء تفعيل دورة الزمن فئن

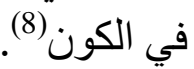

$\left({ }^{3}\right)$ (Leitz 1994),p. 426.

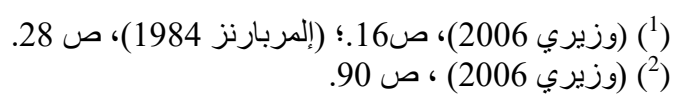

Cf: (Allen 1974), p. 184.; (Bakir 1953), p.110f.

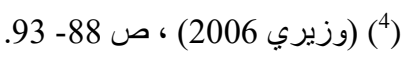

$\left({ }^{5}\right)$ (Borghouts 1971), p. 31, pl. 15.

(') (زيدان2003)، ص 31.

(7) (Derchain 1965) , p. 137.

( $\left.{ }^{8}\right)$ Pyr. 1248, 1652, 1691; CT II 4-5, 18, 174, 23a, 35f, 145b; CT VI 220; CT VII 42f, 489 C. 
المجلة الدولية للتراث والسياحة والضيافة ـ تصدر ها كلية السياحة و الفنادق - جامعة الفيوم،

المجلد (11)، العدد (1/2) سبتمبر 2017

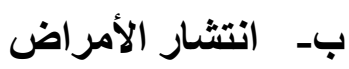

انتشرت خلال أيام النسيء تعاويذ ترتل ثم يقوم الثخص بتلاوتها ثم ارتدائها كتميمة للحماية؛

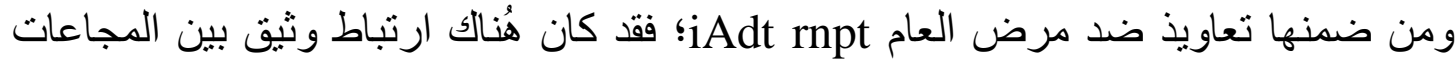

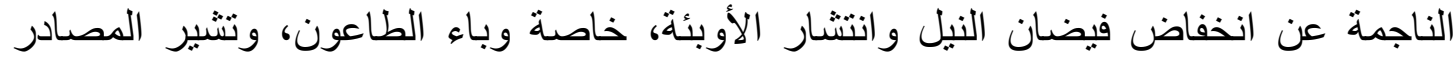

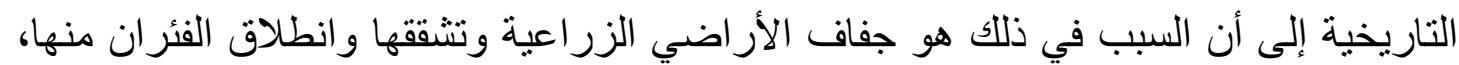
حيث ارتبط وباء الطاعون بظهور هذه الفئران، وكان إنتقال العدوى منها للإنسان الإنسان يتم بواسطة

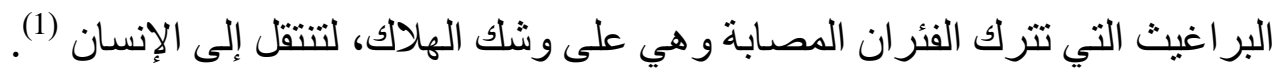

نفثات المعبودة سخمت

كانت أسطورة هلاك البشرية من الأمور التي تخيلها وافترضها الفكر الديني للمصري

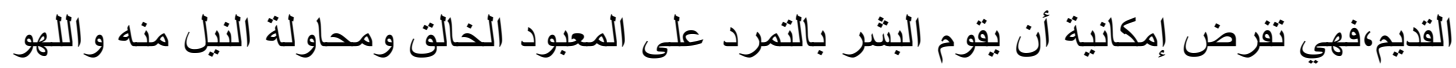

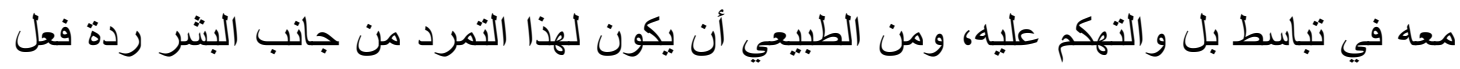

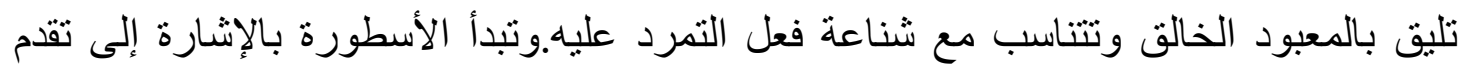

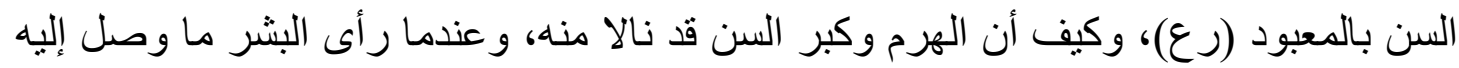

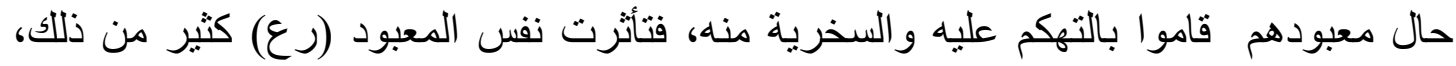

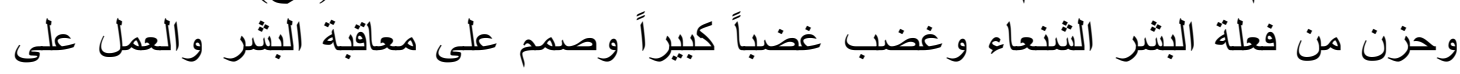

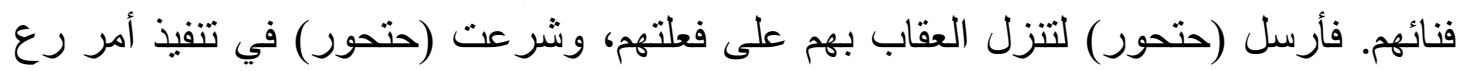

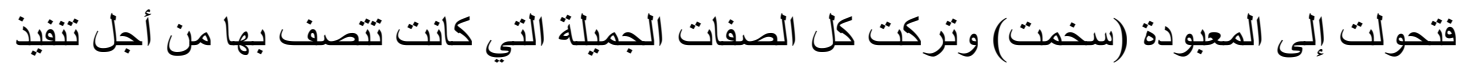

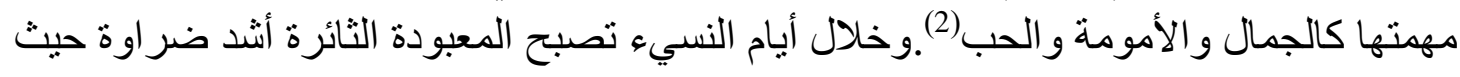

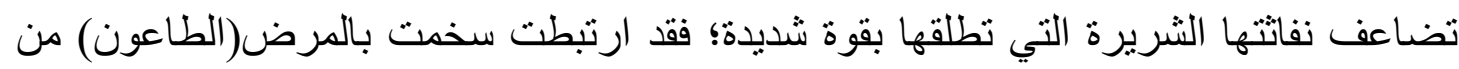

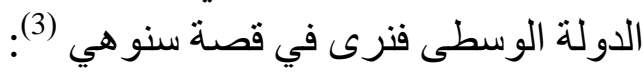
arma

wnn snD.f xt ii (m) xAswt mn sxmt rnpt idw

خشيته موجودة خلال البلاد الأجنبية مثل سخمت في عام الوباء.

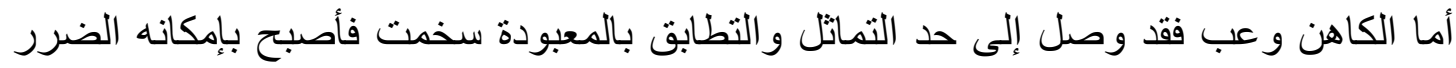

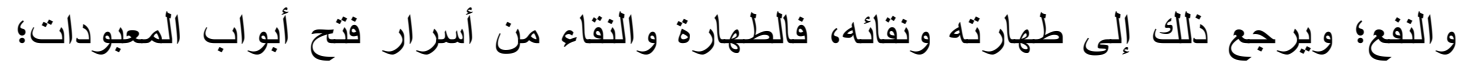

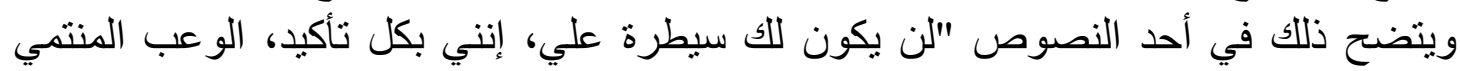

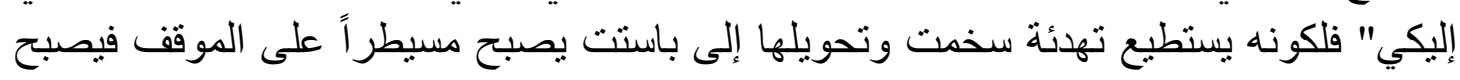

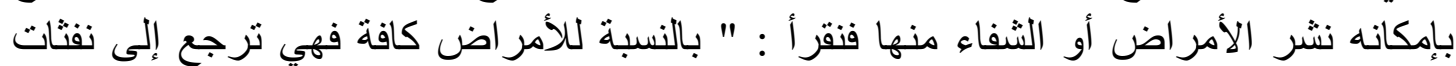

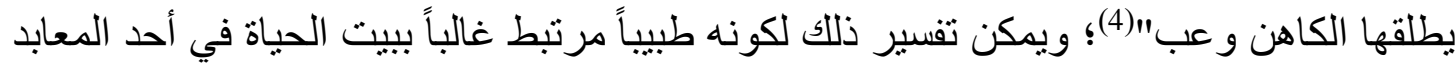

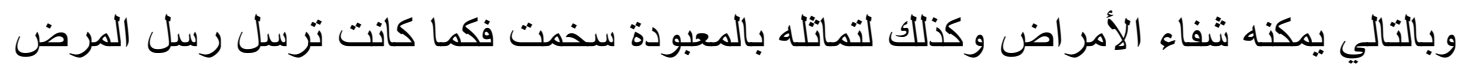

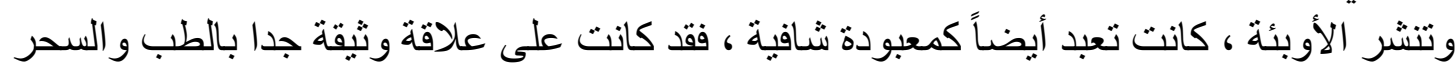

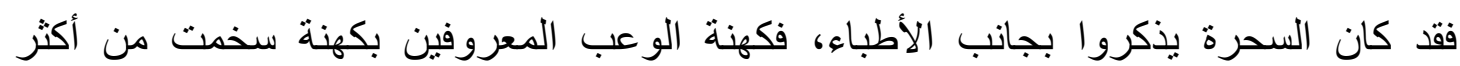

( ${ }^{1}$ (Panagiotakopulu, E. 2004), p.270f

(3) ( Gardiner 1916), p.45.

(نور الدين2009) (209) ص 255.

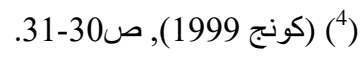


المجلة الدولية للتراث و السياحة والضيافة ـ تصدر ها كلية السياحة و الفنادق - جامعة الفيوم،

المجلد (11)، العدد (1/2) سبتمبر 2017

الممارسين للسحر، وهم كذلك العالمين بطرق الوقاية ودرء الثر و الثنفاء(1)،وقد أبرزت

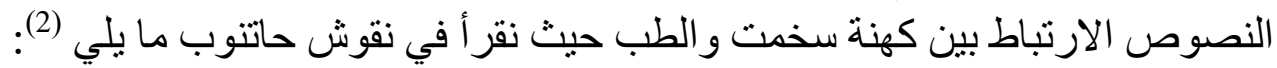

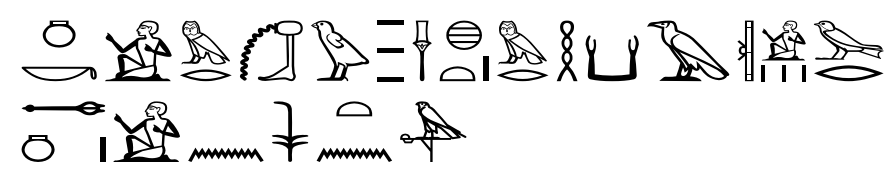

ink imy-r wabw sxmt imy-r HkAw wr swnw n nswt

أنا رئيس كهنة سخمت ، رئيس الكهنة ، كبير أطباء الملك.

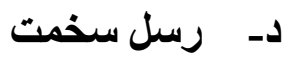

رسل سخمت هي مخلوقات تقف بجانبها وتحت سيطرتها ترسلهم إلى كل الدقاطعات مطلقين

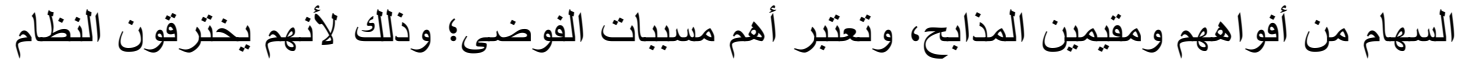

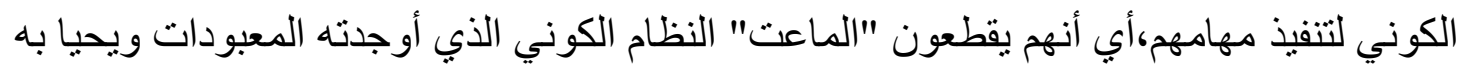

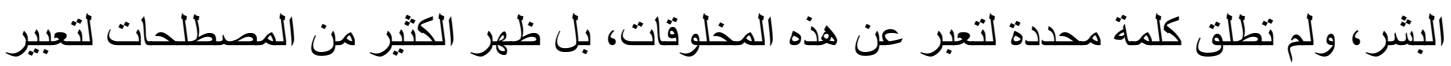

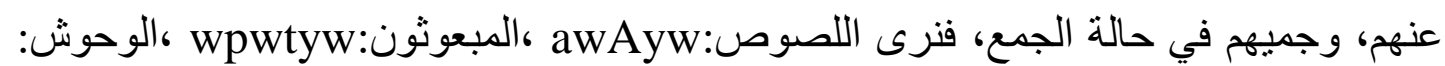

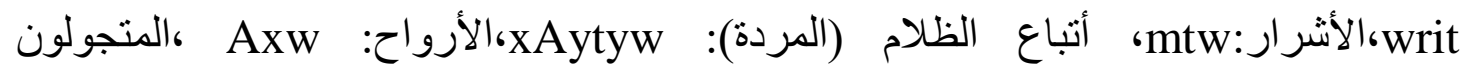
SmAyw:

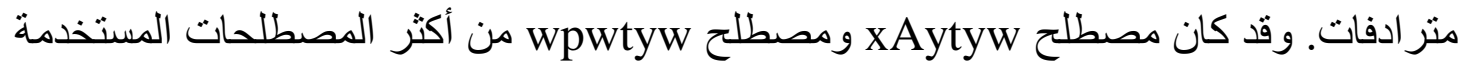
للتعبير عن رسل سخمت خلال ايام النسيء:

\section{أولاً مصطلح}

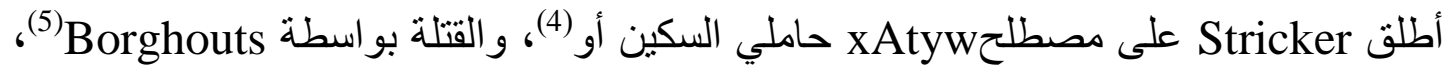

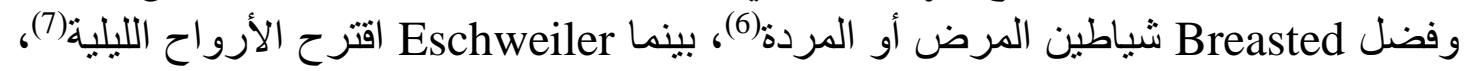

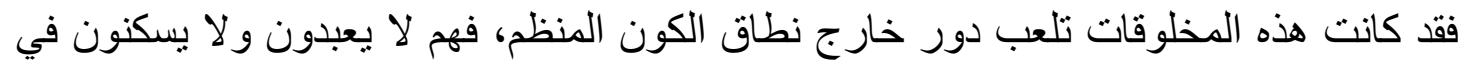

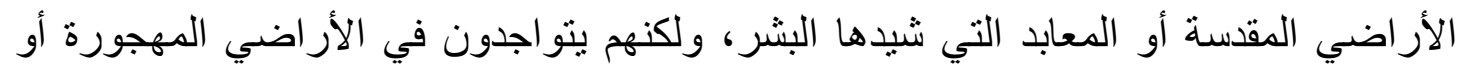

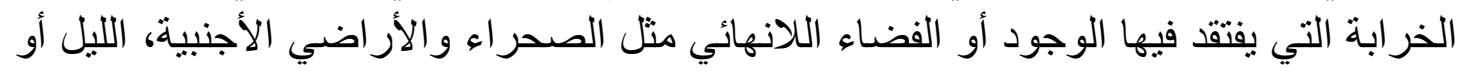

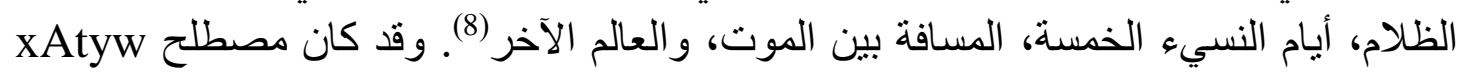
oo

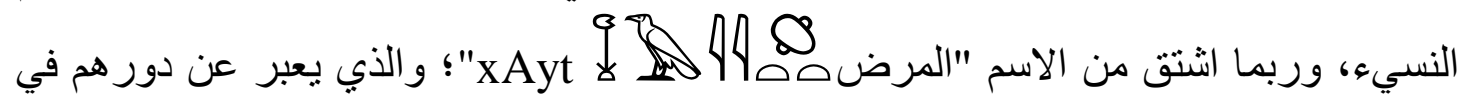

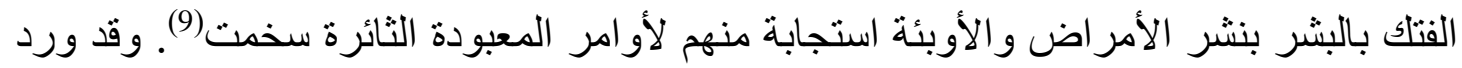

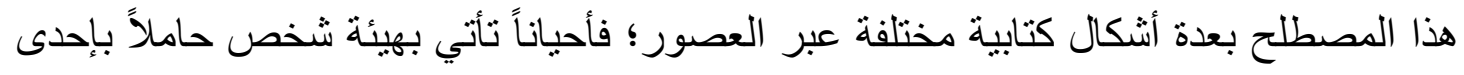

(') (Anthes 1928), 15, 2-3.

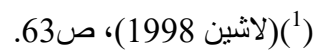

$\left(^{4}\right)$ (Stricker, 1948), p.66.

( $)$ (Borghouts, 1971), p. 12.

( $\left.{ }^{6}\right)$ (Breasted 1930),p. 475.

(7) (Eschweiler 1994), p. 213.

${ }^{8}$ ) (Adhémar, 1954) p.60ff.

(9) WPL, 705f; Dendara, X, 357(16). 
المجلة الدولية للتراث والسياحة والضيافة ـ تصدر ها كلية السياحة و الفنادق - جامعة الفيوم،

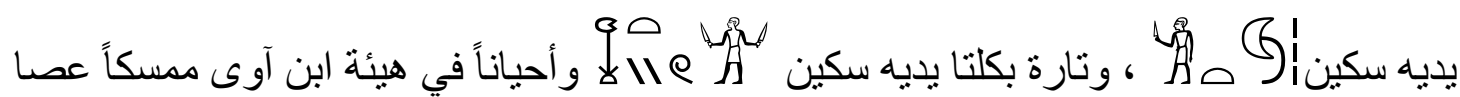

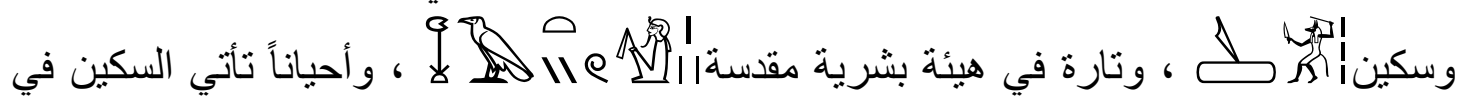
هيئة بيضناوية هـ

شكل3: مشهد يوضح رسل سخمت من معبد إدفو، نقلاً عن : .

Chassinat, E., "Le Temple d'Edfou", Vol. XI, Paris, 1930, Pl. CXII.
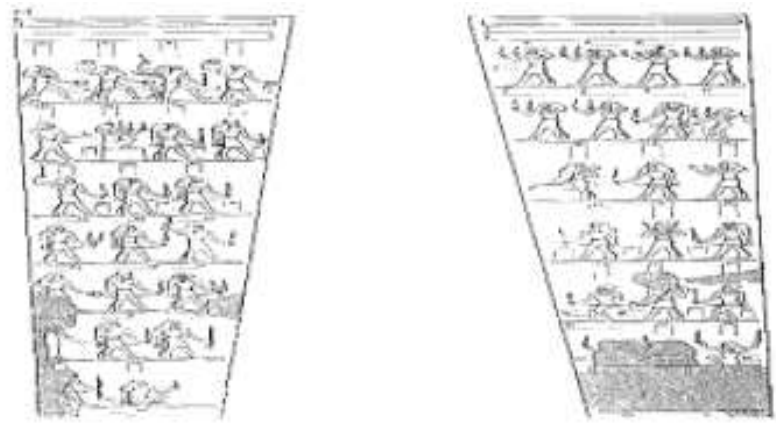

وقد وردت في نصوص الأهر ام ككائنات تقوم بحماية الملك المتوفى فنقر أ (2):

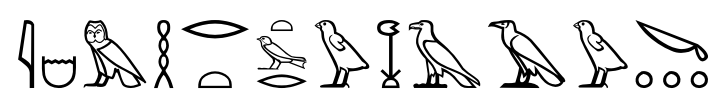

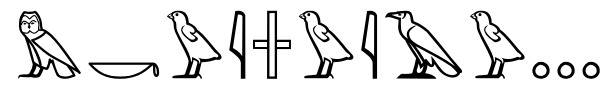

فلتمضي ولتسر ع فإن مردة خانيو في حمايتك.

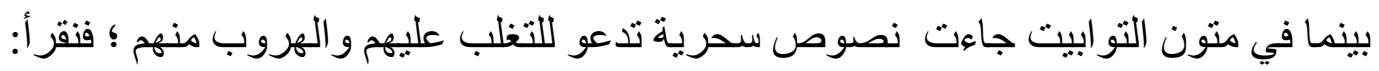

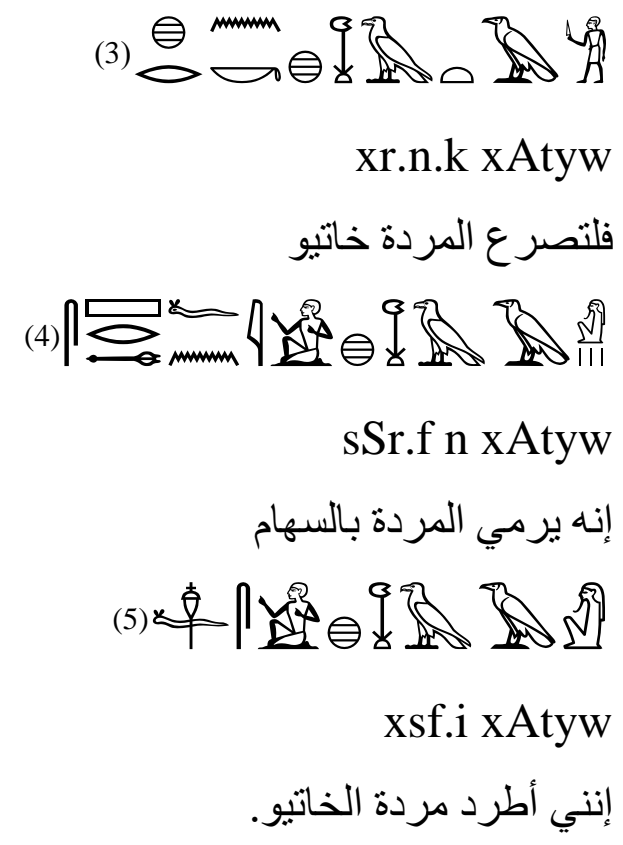

( $\left.{ }^{1}\right)$ LGG, V, 635-637; Wb, III, 236(6-7).

(') Pyr, II, $1265 \mathrm{c}$

$\left(^{3}\right) \mathrm{CT}, \mathrm{I}, 290 \mathrm{~h}$.

( ${ }^{4}$ CT, III, 366 a.

$\left({ }^{5}\right)$ CT, III, 328 a 
المجلة الدولية للتراث و السياحة والضيافة ـ تصدر ها كلية السياحة و الفنادق - جامعة الفيوم، المجلد (11)، العدد (1/2) سبتمبر 2017

وقد ذكرت تعويذة كتاب آخر يوم في السنة من بردية ليدن الأولى 346 أسماء اثنى عشر معبود

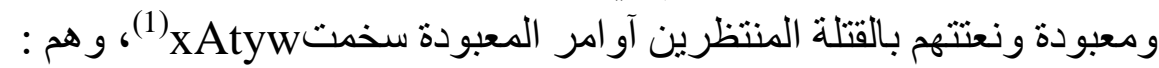

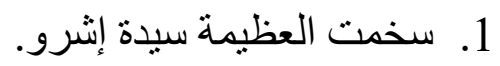

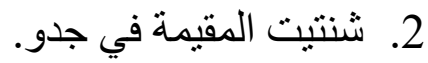

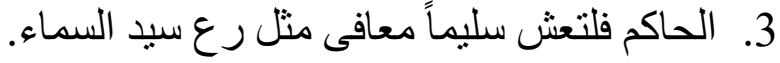
4. شسمتت سيدة بونت. 5. 5. 5ورس سيد بحدت.

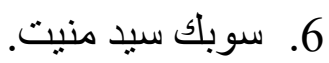

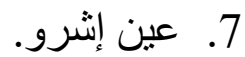

8. عين رع سيد الأرضيين الذي يحكم جزيرة اللهب. 9. ورس المنتمي لأرواح أوبت. 10. من أسفل شجرته ، حور سينه لاروح أشين. 11. 11. عين حورس اللامعة سيدة النبيذ. 12. خنوم سيد بيت الثلاثون (المحكمة).

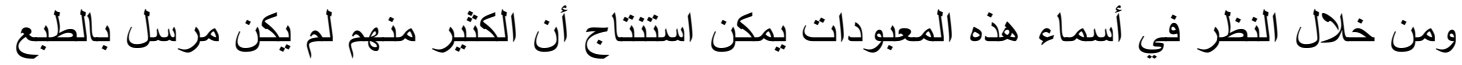

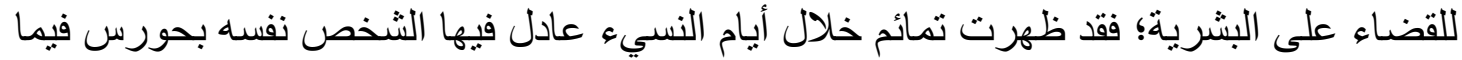

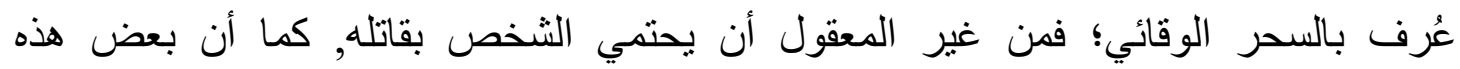

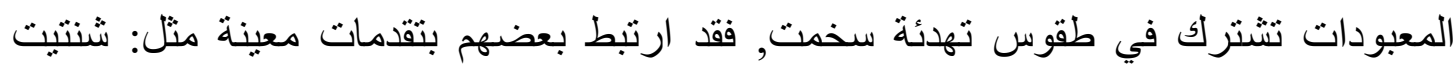

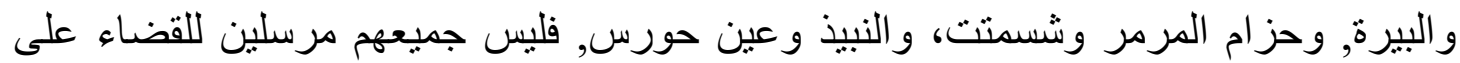

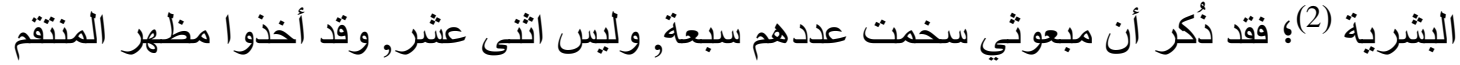

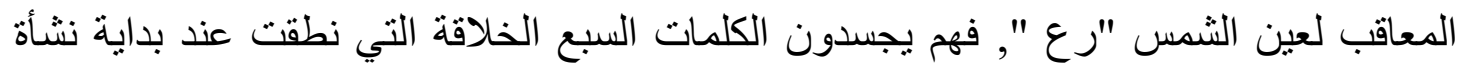

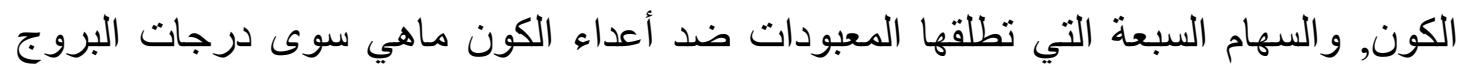

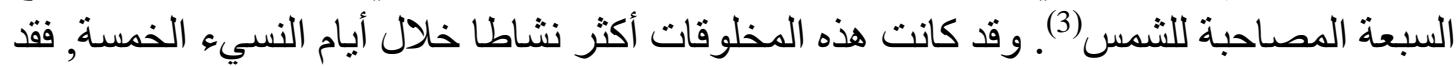

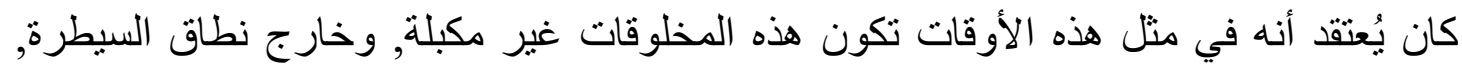

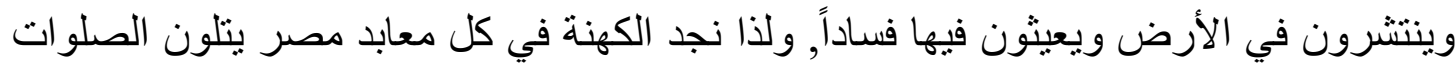

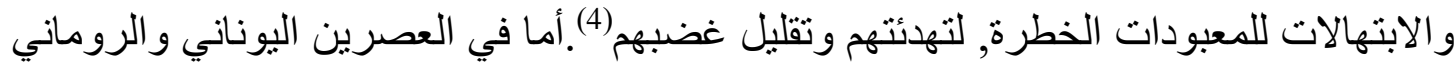

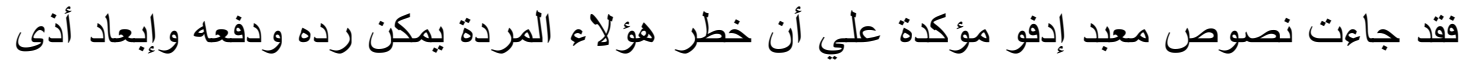
سخمت نفسهاعن شخص الملك من خلال مناجاة حورس و التعبد بمحاسنه وخير اته (5)؛ فنقر أ.

\footnotetext{
(') (Bommas 1999),p.11.

(') (Raven 1997) , p. 283

$\left({ }^{4}\right)$ (Meeks 2001), p.377; Cf: (Szpakowska 2009),pp.799-805.
} 
المجلة الدولية للتراث و السياحة و الضيافة ـ تصدر ها كلية السياحة و الفنادق - جامعة الفيوم،

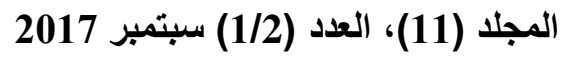

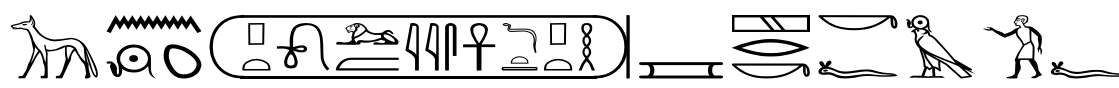

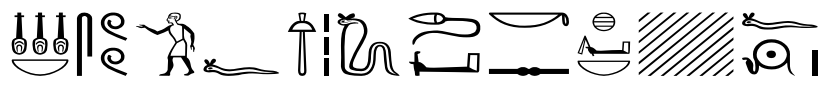

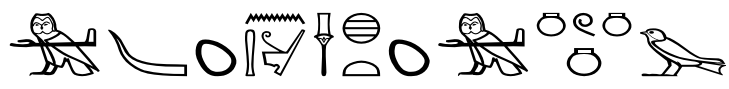

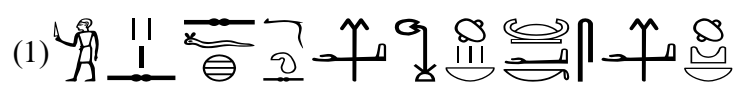

ii.n.i sA RA Ptwlmis anx Dt mry PtH xr.k Ra-@r Axty nb.f iAw.f nfrw.k swAS.fmnxw.k nHn.k sw xw.k ///// .f Ra m ab n Hmt n \%xmt m nwnt

xAtyw.s sfx sw ma xAyt nb wHa.k sy m Dw nb .

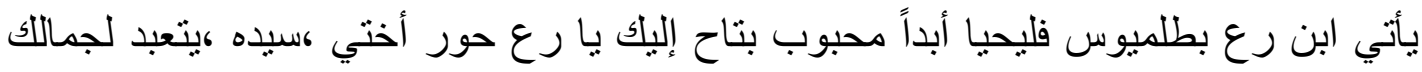

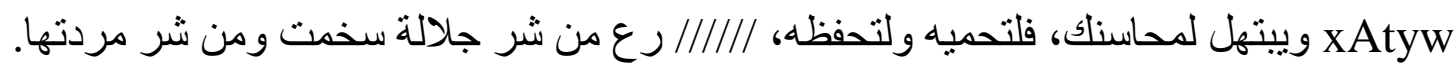

وتحميه من كل مرض وتصون لمونه من كل شر (2).

وقد ذكرت نصوص المعبد أن معرفة الملك لأسمائهم تجعلهم تحت سلطانه؛ فنقر أ (3):

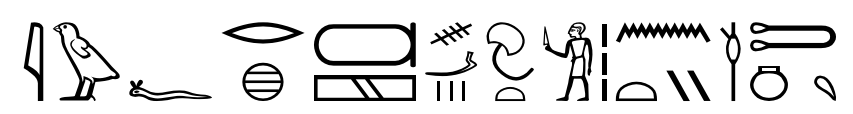

iw.f rx rn SmAyw xAtyw ntyw r-xt wDt n.f.

هو بعلم أسماء رسل مردة خاتيو الذين تحت أمره(4).

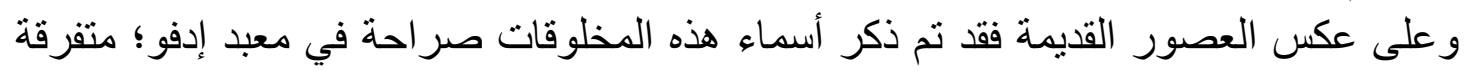
على الفصول الثلاثة للعام (5).

\section{ثانياً مصطلح إن}

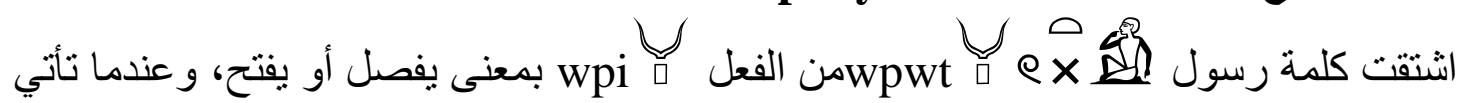
بمعنى رسالة أو مهمة تأتي بالمخصص هـ (6) وند إضافتها لكلمة nsw تظهر بالثكل الكتابي

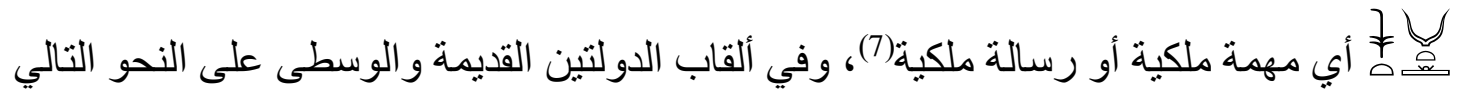

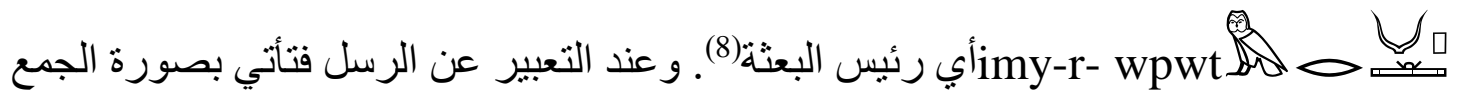

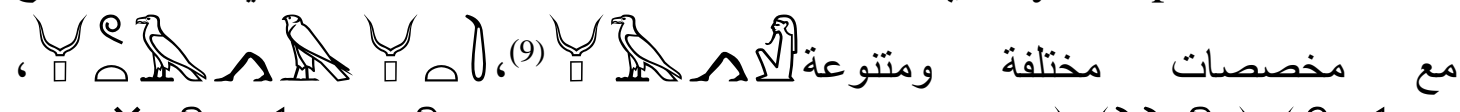
د

$\left({ }^{1}\right)$ Edfou, III, 17 (7), III, 33, VI, 300 (15).

$\left({ }^{3}\right)$ Edfou, III, 322 (12).

(5) Edfou, V, 11f ; 104f.

(2) (2) (2014) (2014)، ص 338.

$\left.{ }^{6}\right) \mathrm{Wb}, \mathrm{I}, 303(8-9)$

$\left({ }^{7}\right) \mathrm{Wb}, \mathrm{I}, 303(10)$

$\left({ }^{8}\right) \mathrm{Wb}, \mathrm{I}, 303(14-16)$.

(9) CT, I, 196d.

$\left({ }^{10}\right) \mathrm{CT}, \mathrm{V}, 54 \mathrm{~b}$. 
المجلة الدولية للتراث والسياحة والضيافة ـ تصدر ها كلية السياحة و الفنادق - جامعة الفيوم، المجلد (11)، العدد (1/2) سبتمبر 2017

و الجدير بالإشارة أن هناك أنواع من الرسل؛ فمنهم رسل المعبودات wpwtyw-nTrw، ورسل الربل

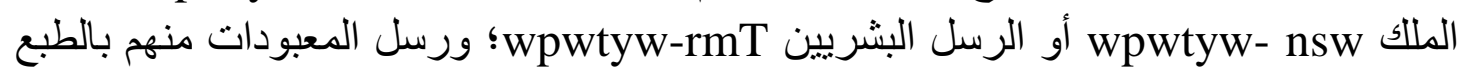

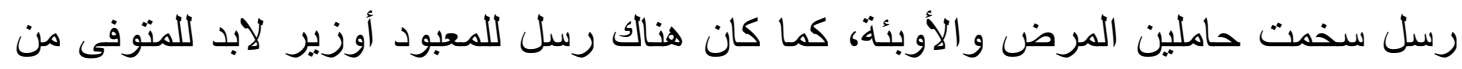

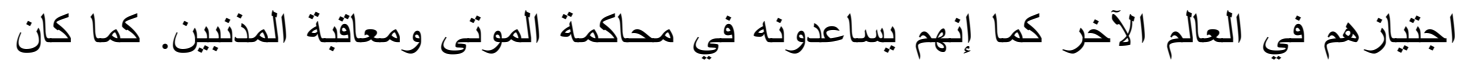

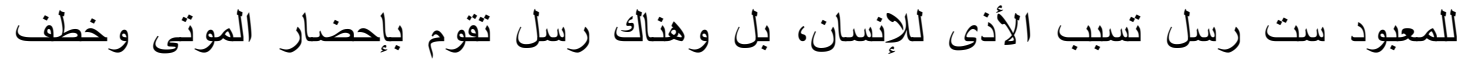

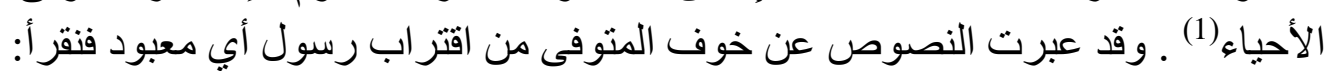

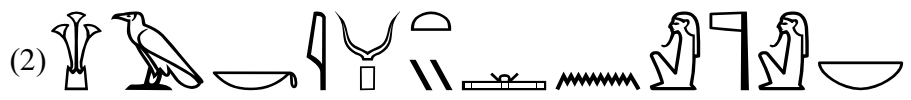

HA.k wptyw n nTr nb تر اجع يا رسول أي معبود.

• سبل النجاة والطرق الوقائية خلال أيام النسيء الخمسة تعتبر بردية ليدن الأولى 346 بمثابة نموذج صرية لألثريح لما يحدث خلال أيام النسيء من تدابير وقائية

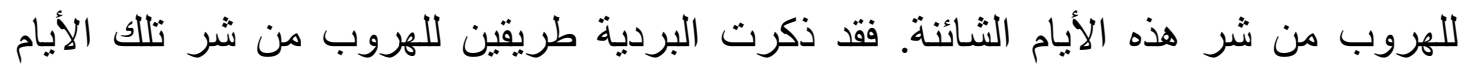

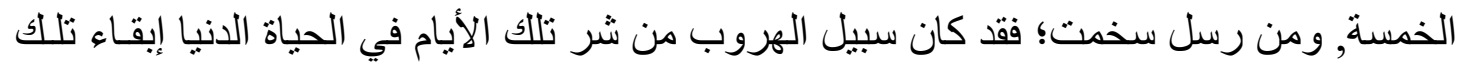

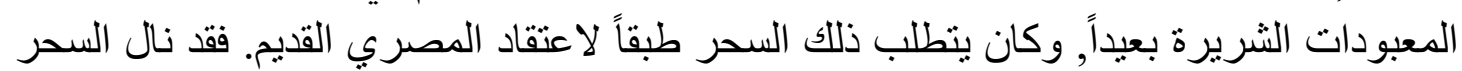

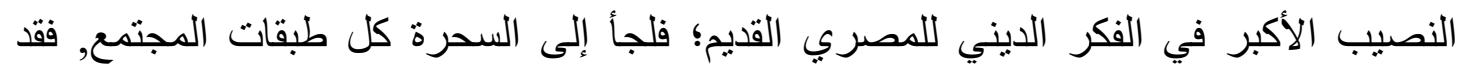

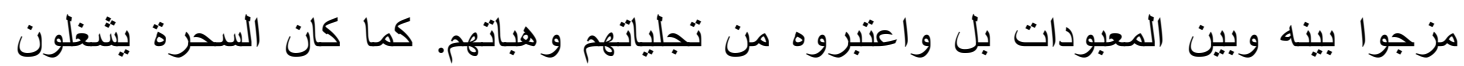

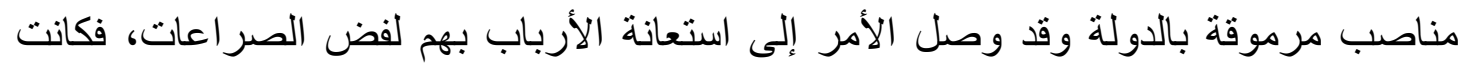

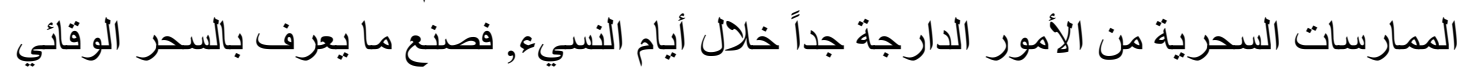

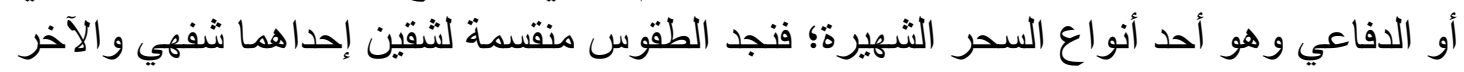

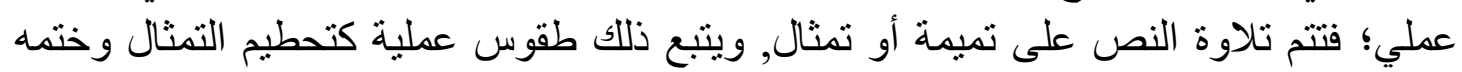

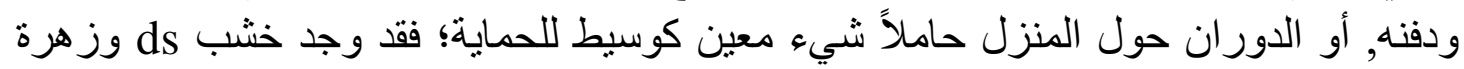

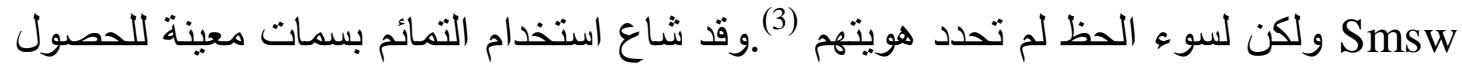

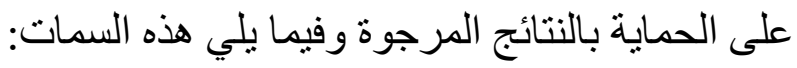

\section{الأقمشة المُستخدمة في صناعة التمائم السحرية}

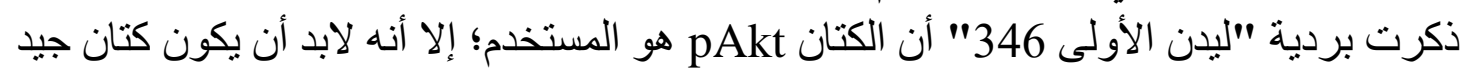

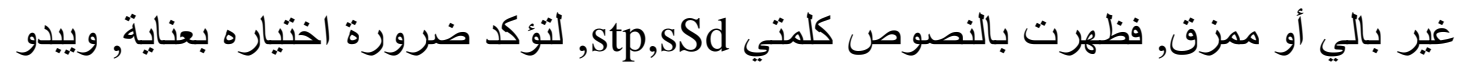

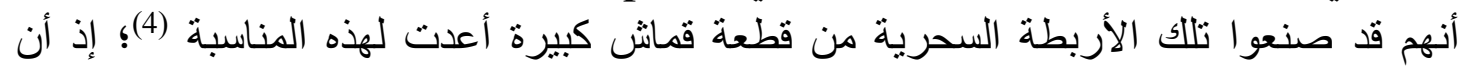

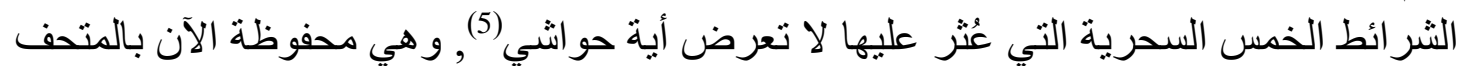

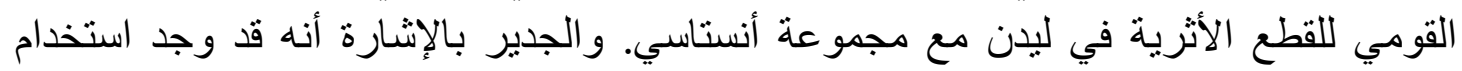
للبردي في صناعة التمائم السحرية، وربما اقتصر استخدام الكتان للملوك و ولية القوانية القوم فقط. وطبقاً

$\left(^{2}\right) \mathrm{CT}, \mathrm{V}, 55 \mathrm{~b}$.

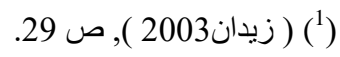

$\left({ }^{4}\right)$ (Pinch, 1994), p.80.

. (كونج, (1999) , ص (193)

( $)$ (Raven, M., 1997), p.297. 
المجلة الدولية للتراث و السياحة والضيافة ـ تصدر ها كلية السياحة و الفنادق - جامعة الفيوم، المجلد (11)، العدد (1/2) سبتمبر 2017

لبردية "ليدن الأولى 346" فقد أستخدم للرسم على الكتان لون يتداخل مع الذهب, يطلق عليه qnit:

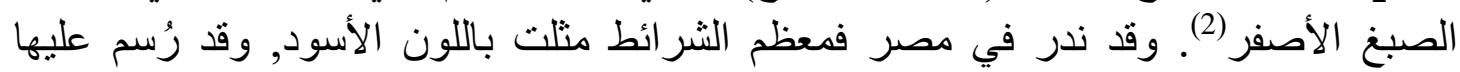

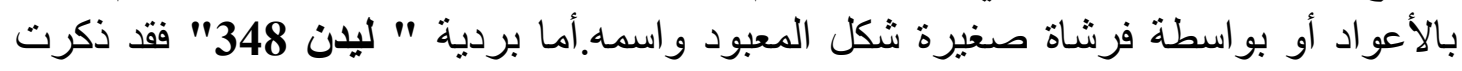

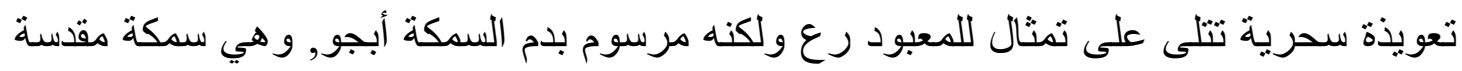

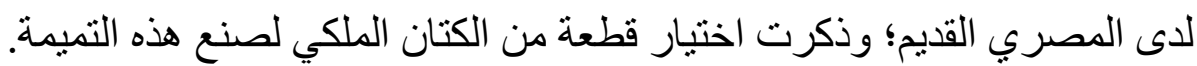

شكل 4: مشهد يوضح تميمة مصنو عة من الكتان مدون عليها السحر ، نقلاً عن: إيفان كونج, إنها

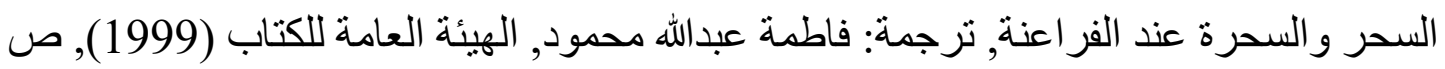

.273

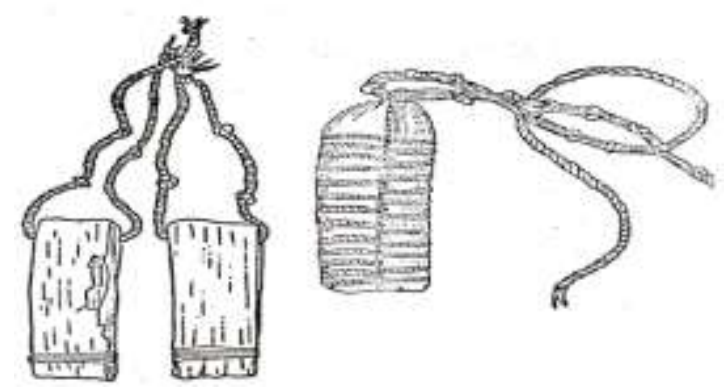

عدد عُقد التمائم السحرية ورمزيتها الاينية

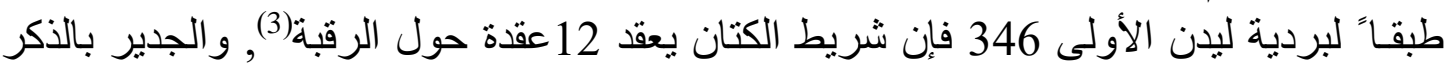

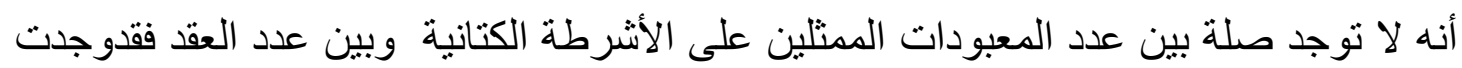

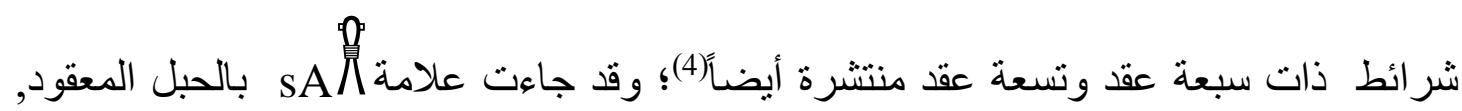

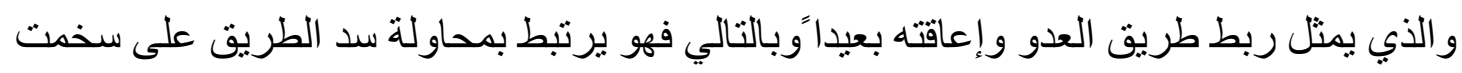

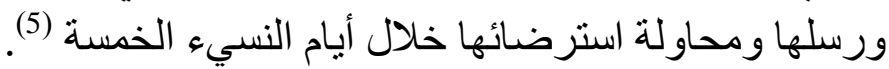

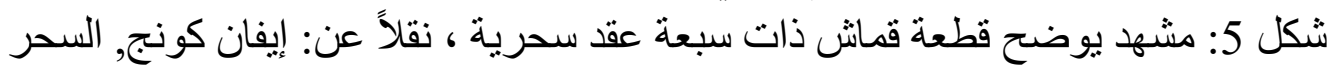

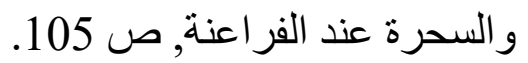

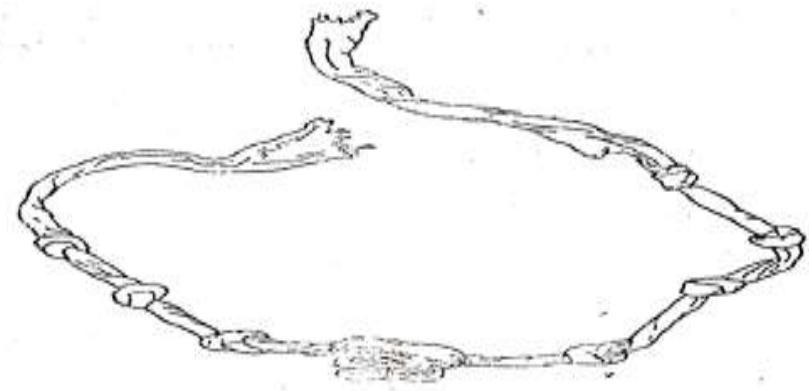

( ${ }^{1}$ (Eschweiler 1994), p.251; (Bommas, 1999),p.17f.

$\left({ }^{3}\right)$ (Bommas, 1999), p.14.

( ${ }^{5}$ (Pinch, 1994), p.83f. ;( Raven, 1999),p.280. 
المجلة الدولية للتراث و السياحة والضيافة ـ تصدر ها كلية السياحة و الفنادق ـ جامعة القيوم،

ربط التمائم السحرية حول الرقبة

كان ذلك يعكس مدى إدرالك المصري القديم لأهمية الرقبة كأحد القنوات الرئيسية للحياة فهو يوصل الهواء والطعام والماء والدم ؛ وقد استخدمت كلمة Ts, Tst للتعبير عن العنق وفقر اته؛

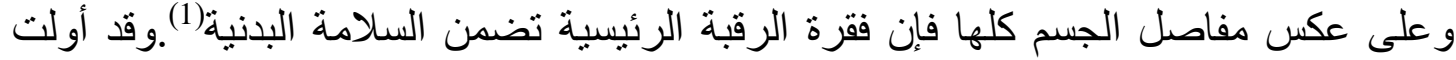
نصوص الأهر ام اهتمام خاص بالر أس و عدم انفصاله عن الجسد, بينما كان وسيلة فعالة للقضاء

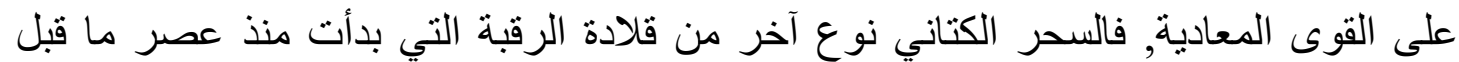

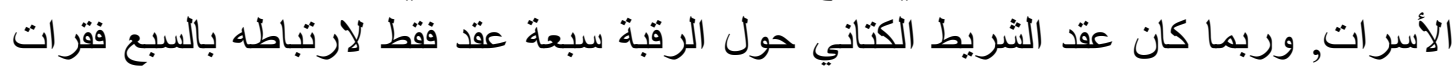
عنقية للرقبة(2). وقد اختلف تفسير السبع فقرات في بردية" لبدن 345/343"؛ فقد ارتبطت لرت

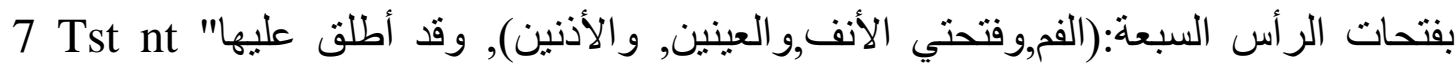
"DADA تطبيق هذا السحر الكتاني حول الرقبة لم يكن من قبيل المصادفة؛ فمن المعروف طبياً إمكانية

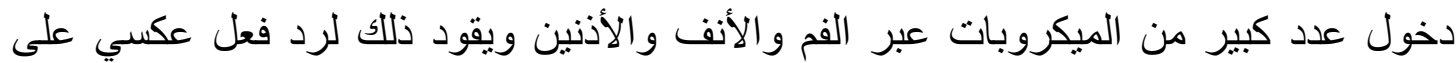
اللوزتين و الغدد الليمفاوية وباقي الغدد في منطقة الرقبة. ولذلك كان لديهم اعتقاد راسخ بإمكانية الحماية وتوفير السلامة البدنية فالربط يربط القوى المعادية ويحمي من الطاعون هذا العام الذي فئي

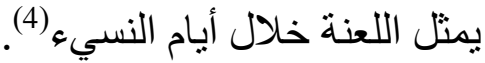

\section{ب- معرفة مسميات أيام النسيء الخمسة}

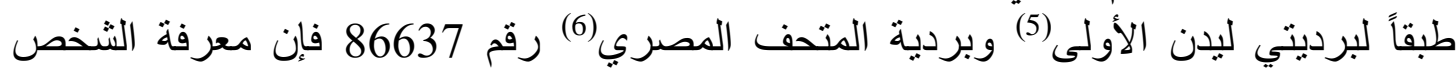

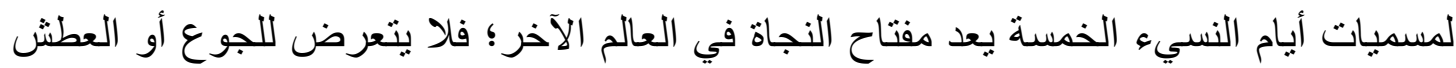

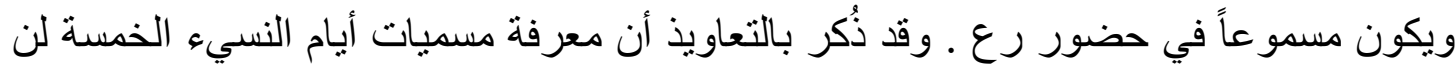
تجعل المتوفى يدخل قاعة المحكمة. وقد ذكر المتوفى أن "حو" سوف بحميه؛ وهو المعبود داء

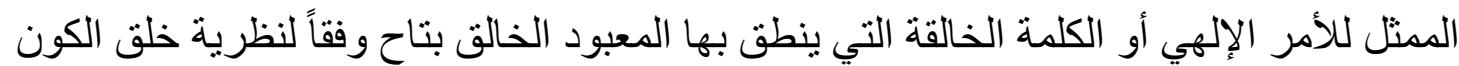
في "منف". وقد ظهر ارتباط حو بالمتوفي في كتاب الموتى الفصل (131) حيث يتحدث المنتوفي

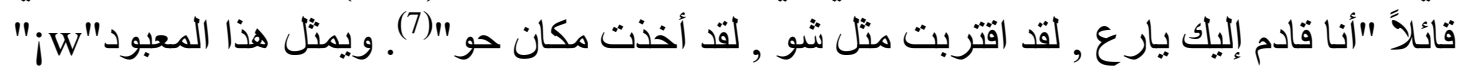

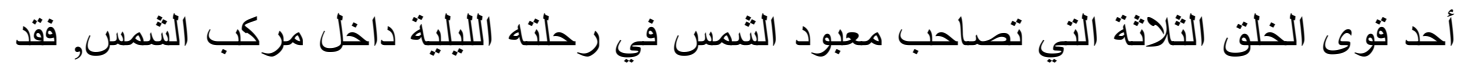

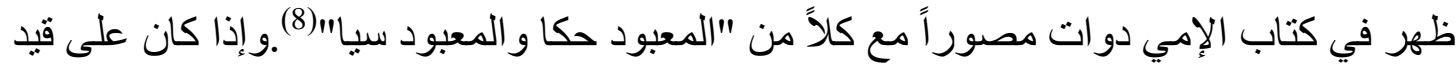
الحياة فلن يمرض أو يموت بالداء المنتشر؛ فلن تسيطر سخمت ورن ورسلها عليه.

\section{ج- تقديم القرابين للمعبودات} يتضح من خلال الفصل (148)(9)من كتاب الموتى أهمية التعبد وتقديم قر ابين الطعام والجعة و البخور المحترقة للمعبودات, وقد أثنار النص لمعبودات النسيء "بهؤلاء المعبودات المرسومين

( ${ }^{1}$ ) (Traut 1988),8-14.

( ${ }^{2}$ (Pinch, 1994), p.111f; Pyr, I, 511 b.

$\left(^{3}\right)$ (Adhémar, 1954), vso,V, n.6.

$\left(^{4}\right)$ (Ritner, 1993),p.168.

(5) (Bommas, 1999), p. 15.

(') (Bakir, 1966), p.50, Vs, X.

(9) (Budge, 1898) , p. 366. 
المجلة الدولية للتراث والسياحة والضيافة ـ تصدر ها كلية السياحة و الفنادق - جامعة الفيوم، المجلد (11)، العدد (1/2) سبتمبر 2017

باللون الأحمر "؛ فقد شاعت صناعة تمائم حمر اء كتانية خلال أيام النسيء (1), كما ذُكر في بردية

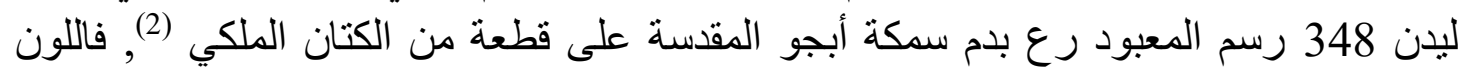

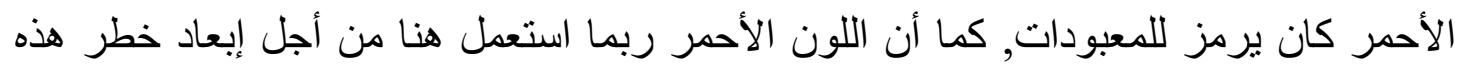

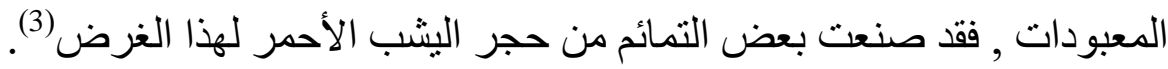

دـ تماثيل الأوشابتي ومدى دلالتها خلال أيام النسيء

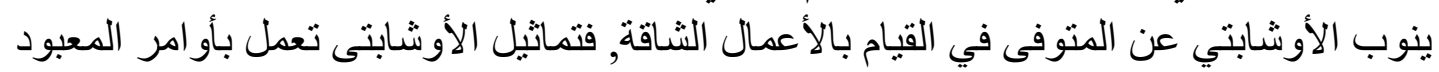

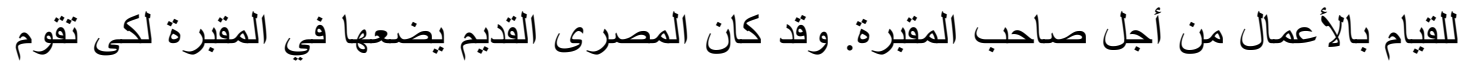

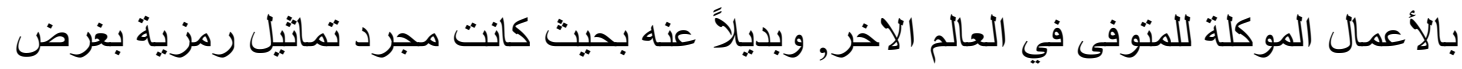

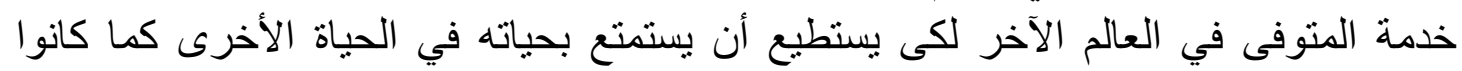

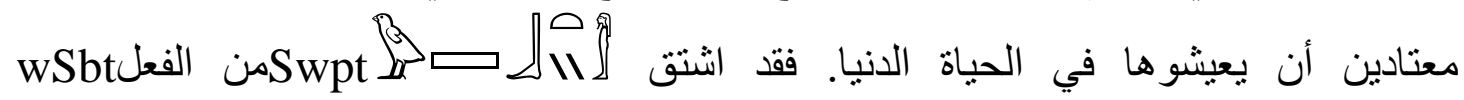

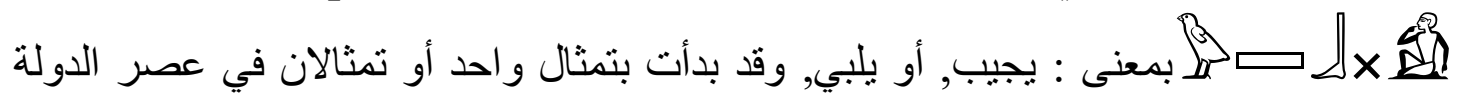

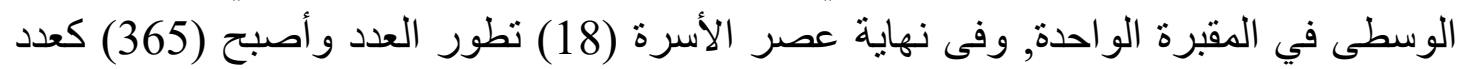

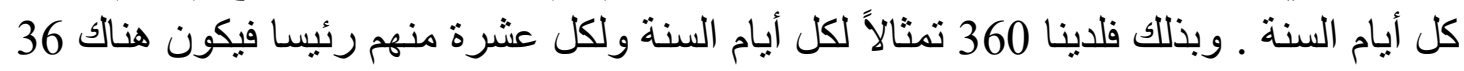

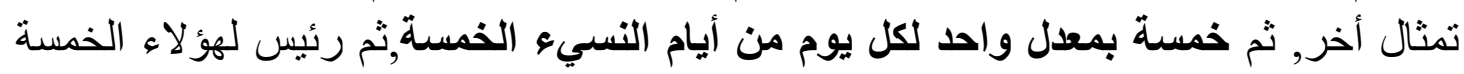

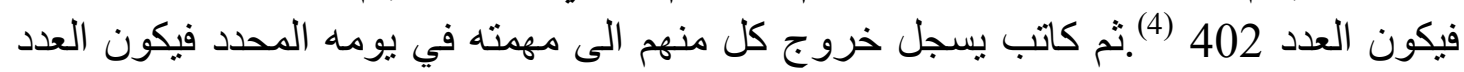

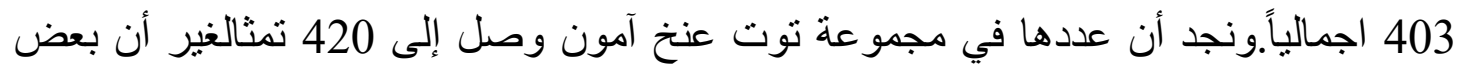

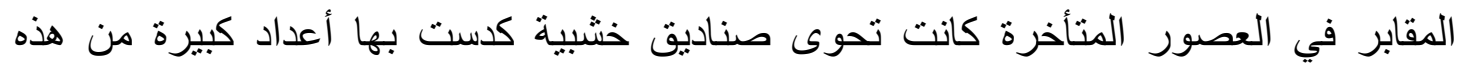

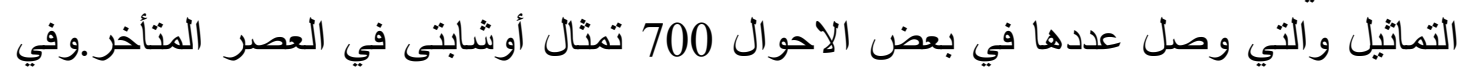

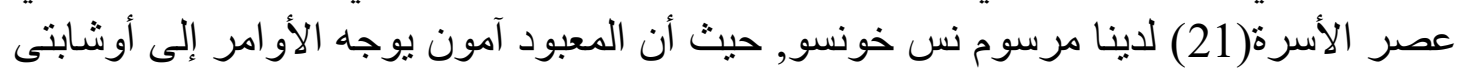

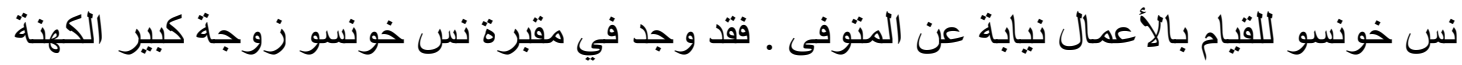

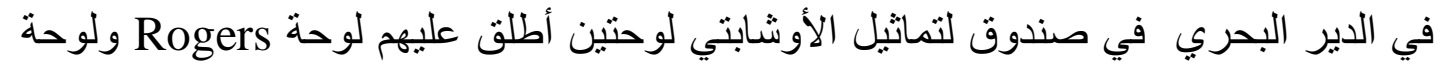

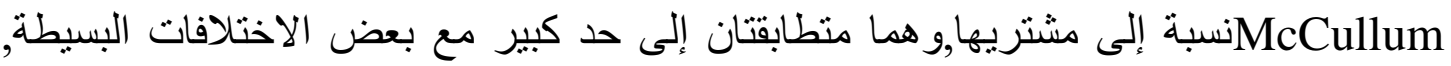

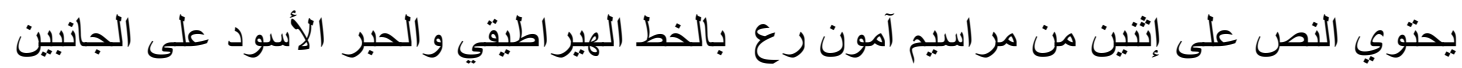

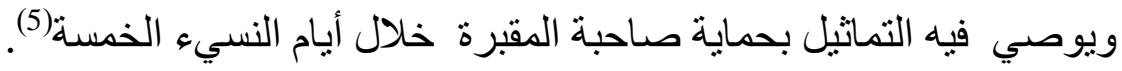

\section{هـ طقوس تهائة سخمت خلال أيام النسيء}

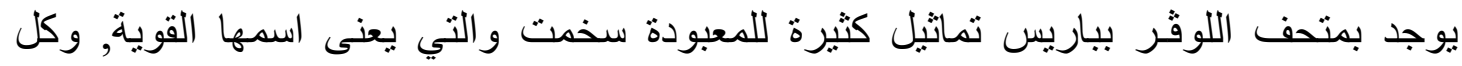

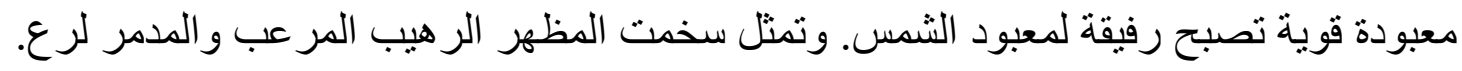

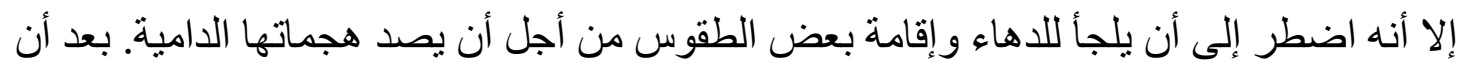

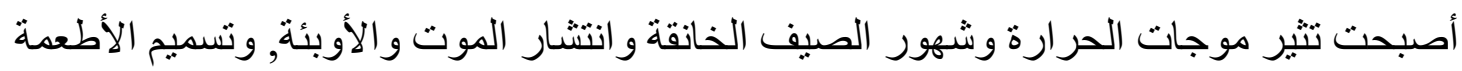

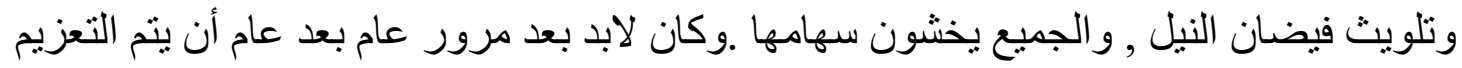

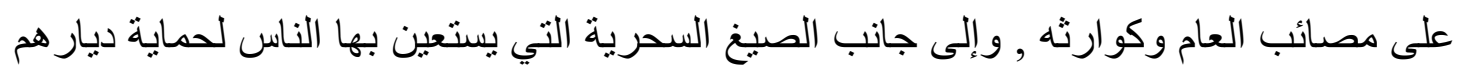

$\left({ }^{1}\right)$ (Bommas, 1999), p.13.

$\left.{ }^{2}\right)$ (Borghouts , J., 1971), p.22, spell 13, Pl.18.

$\left({ }^{5}\right)($ Heel 2014),p.169f. 
, فالضرورة تستلزم تحويل المعبودة الخطرة إلى معبودة مهدأه(1). و الجدير بالإشارة أن دلائل

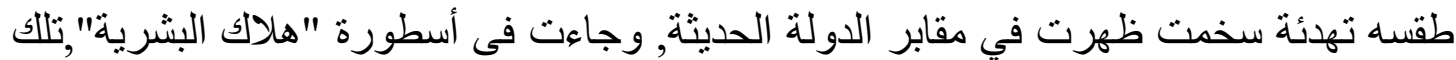

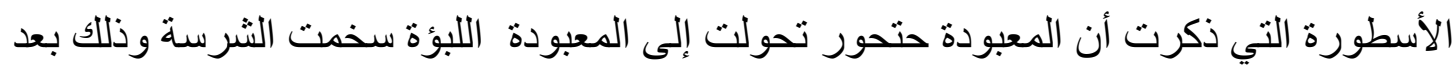

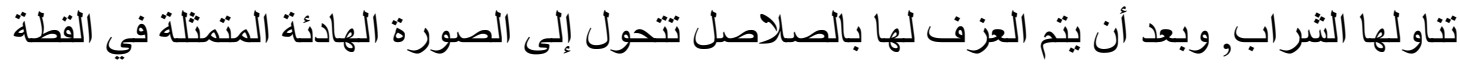

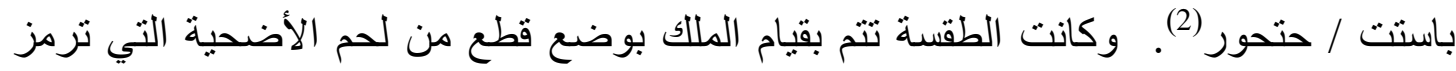

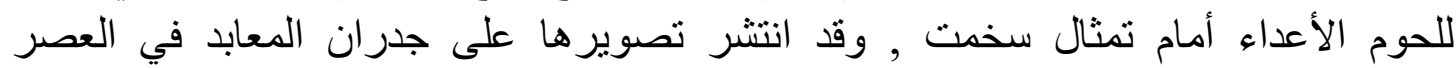

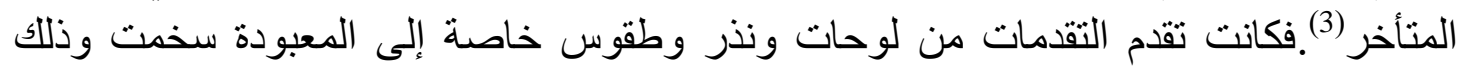

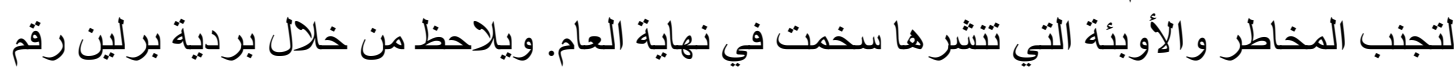

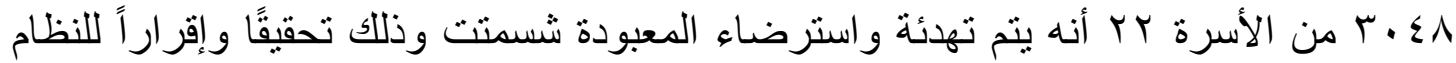

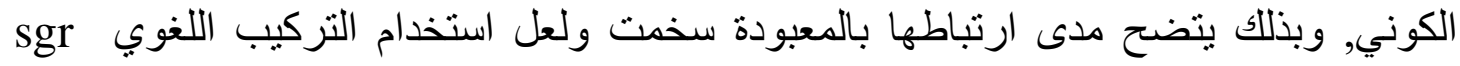

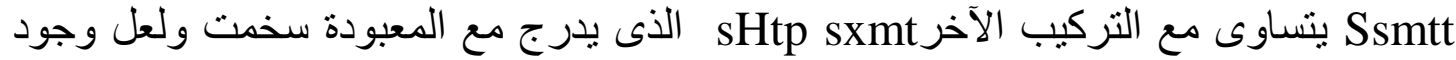

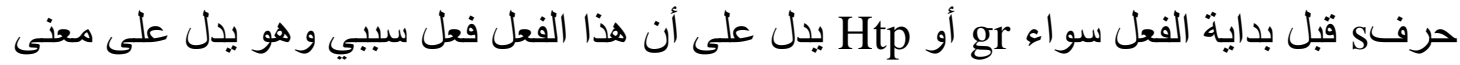

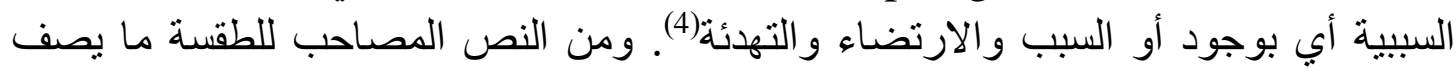

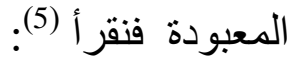

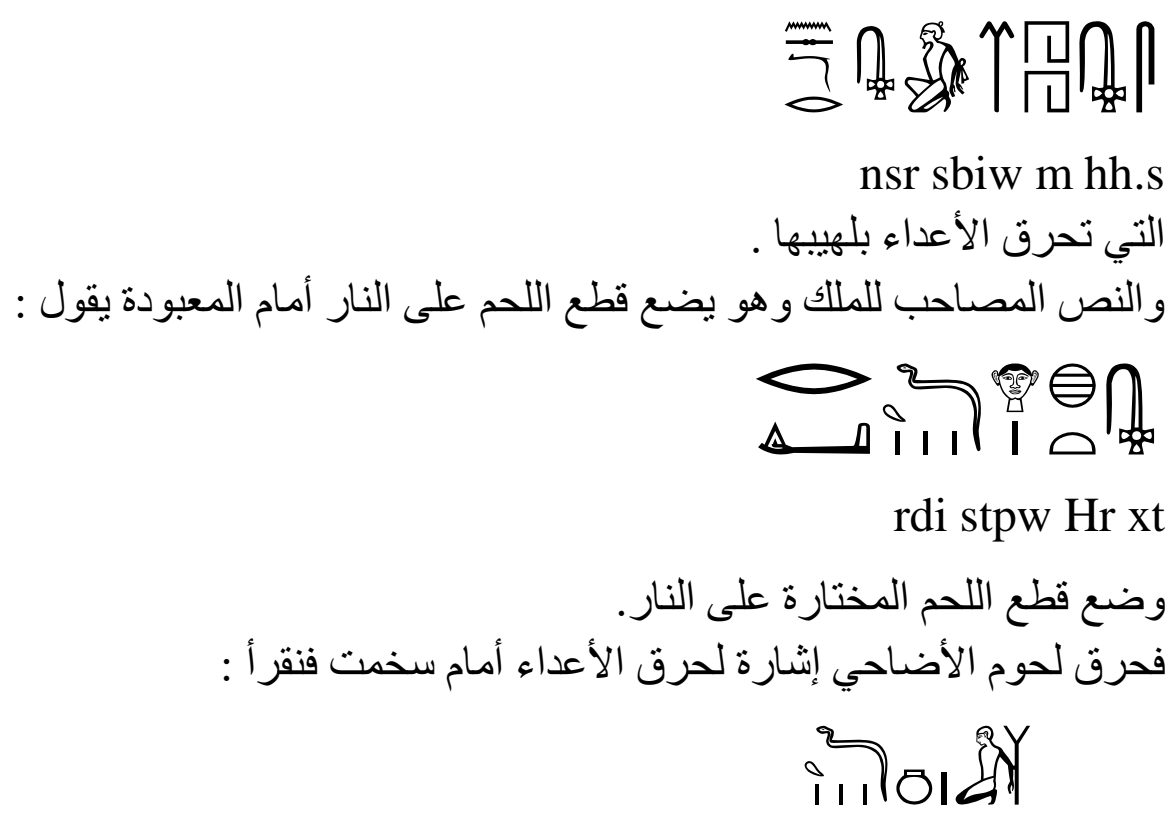

Stpw nw sbiw

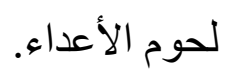

فالمخصص | المصور وقد شُد إلبه وثاق أسبر , هو عمود للحرق , حيث كانت تنفذ عقوبة الإعدام فيمن حكم عليه بثده لهذا العمود ثم حرقه (6). وتتمثل القر ابين والتقدمات المقدمة لتهدئة

$\left(^{4}\right)$ (François 1975), cols.724 -727.

$\left({ }^{5}\right)$ Dendérah, III, P1.52. 
المجلة الدولية للتراث والسياحة والضيافة ـ تصدر ها كلية السياحة و والفنادق - جامعة الفيوم،

المجلد (11)، العدد (1/2) سبتمبر 2017

سخمت في: ذبح الأوزات الأربعة ، ذبح أربعة من الثيران(1)، تقديم أباريق النبيذ والجعة ، تقديم

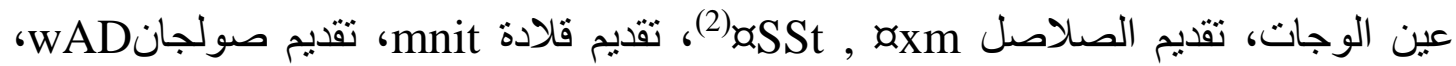
تقدمة

قائمةً المراجع: الإختصارات

CT = De Buck, A., "The Egyptian Coffin Texts", 7 vols., Chicago, 1935-1961.

Dendérah = Marriette, A., " Dendérah, Déscription générale du grand temple de cette ville ", 4 vols., Paris, 1870-1875.

Edfu = Chassinat, E., "Le Temple d'Edfou",7 vols. I-XIV, MMAF X-XI, XX-XXXI, Paris, 1897-1934.

L̈̈ = Helck, W. \& Otto, E., "Lexikon der Ägyptologie", 7 vols.,Wiesbaden 19751986.

LGG = Leitz, ch. Lexikon der Ägyptischen Götter und Götterbezeichungen, OLA, 7 vols, Leuven-Paris-Dudley, 2003.

Naville, Tb. = Naville, E., "Das Ägyptische Totenbuch der 18-20 Dynastie ", 3 vols., Berlin 1886.

PT $=$ Sethe, K., "Die Altägyptischen Pyramiden Texte ", vols. I-II, Leipzig 19081910.

Wb = Erman, A.,\& Grapow, H., Wörterbuch der Ägyptischen Sprache, hrsg, 7 vols., Berlin, 1971.

WPL = Wilson, P., a Ptolemaic Lexikon a lexicographical study of The texts in The temple of Edfu, OLA, 78, Leuven, 1997.

ثانياً: المراجع العربية

أحمد إبر اهيم علي أحمد زيدان، (2003)، الرسل في مصر القدية القيمة حنى نهاية الدولة الحديثة ، رسالة ماجستير غير منشورة ، كلية الآثار ، جامعة القاهرة

أحمد خلف الله سفينة، (2014)، مردة xAtyw في نصوصة، معبد إدفو، المؤتمر الدولي الأول، كلية الآثار،

جامعة الفيوم.

أيمن عبد الفتاح حسن وزيري، (2006)، المصطلحات المعبرة عن الزمن في مصر القديمة حتى نهاية الدولة الحديثة( در اسة لغوية حضارية) مخطوطة رسالة ماجستير غير منشورة، القاهرة.

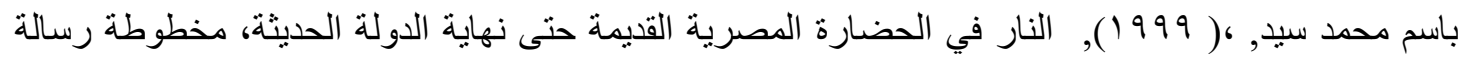
ماجستير غير منشورة، جامعة القاهرة، كلية الآثار.

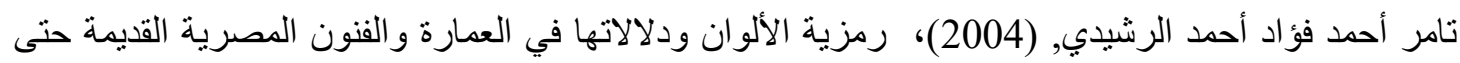

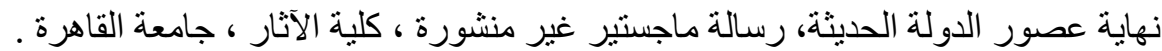

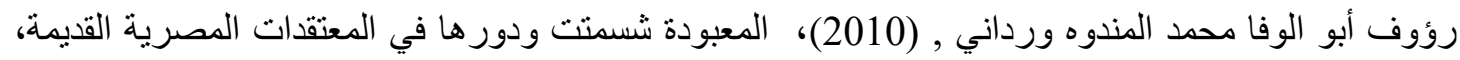

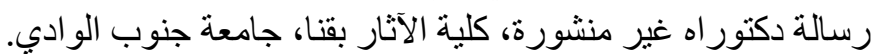

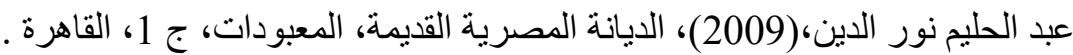

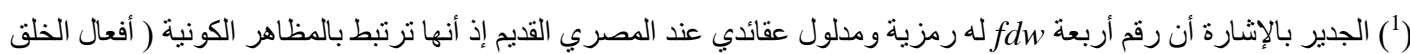

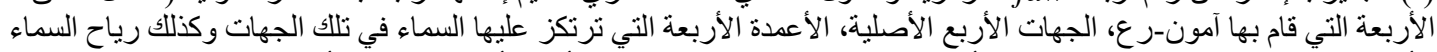

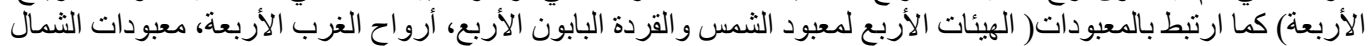

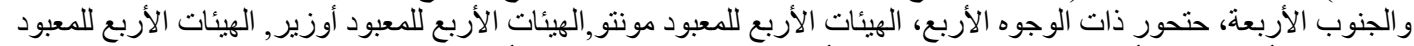

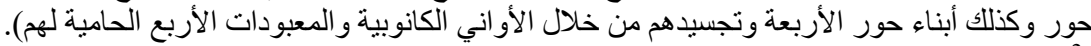

$\left(^{3}\right)$ (Germond 1981), pp. 251-272.

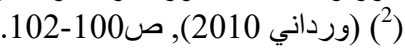


المجلة الدولية للتراث و السياحة والضيافة ـ تصدر ها كلية السياحة و والفنادق - جامعة الفيوم،

المجلد (11)، العدد (1/2) سبتمبر 2017

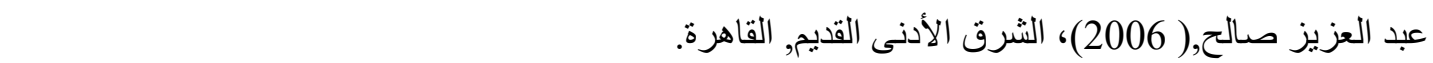
عماد عبد التواب لاشثين، (1998)، اللبؤة في مصر القديمة الإنى حنى نهاية الدولة الحديثة ، رسالة ماجستير غير منشورة، كلية الآثار ، جامعة القاهرة.

وليم نظير،(1970) الثروة النباتية عند قدماء المصريين، الهيئة المصرية العامة للتأليف والنشر،القاهرة.

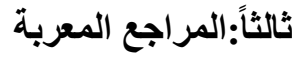

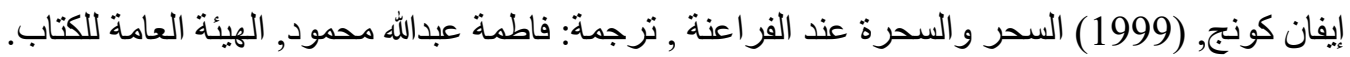

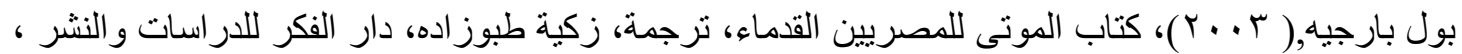
القاهرة. فر انثي ماسيميليانو ،(2005)، الفلك في مصر القديمة، ترجمة : فاطمة فوزي، الطبعة الأولى ، المركز القومي للترجمة . هاري إلمربارنز، (1984)، ناريخ الكتابة التاريخية، ترجمة : محمد عبد الرحمن، ج1. رابعاً: المراجع الأجنبية

Adhémar, M., ( 1954) ,The Leiden magical papyrus I 343 + I 345,OMRO 34, Leiden. Allen, J.P., (2010), Middle Egyptian, An Introduction to the Language and culture of Hieroglyphs, Cambridge.

Allen, G., (1974) ,The Book of The Dead, Chicago.

Anthes, R., (1928), Die Felseninschriften von Hatnub nach den Aufnahmen Georg Möllers, Leipzig.

Bakir, A., (1953), "Difference between nHH and Dt", JEA, 39. , (1966), The Cairo Calendar. No. 86637, Cairo.

Bommas, M., (1999),Die Mythisierung der Zeit: Die beiden Bücher über die Altägyptischen Schalttage des magischen P. Leiden 346,GoFIV, 37, Wiesbaden .

Breasted, J., H , (1930), The Edwin Smith surgical papyrus, Chicago.

Borghouts , J., F. , (1971), The Magical Texts of Papyrus Leyden I 348, Leyden.

Budge, W., (1898), The Book of the Dead ,The Chapters Of Coming Forth by day, London.

Derchain, Ph., (1965), Papyrus Salt 825 (BM 10051), Ritual Pour La Conservation de La Vie en Egypte, Bruxelles.

Eschweiler, P. , (1994), Bildzauber im alten Ägypten: die Verwendung von Bildern und Gegenstanden in magischen Handlungen nach den Texten des Mittleren und Neuen Reiches Freiburg .

François, D., (1975), Besänftigung, LÄ I.

Gardiner, A.,H, (1916), Notes on the story of Sinuhe, Libraries Honoré Champion, Paris.

Germond, Ph., (1981), Sekhmet et la protection du monde.

Heel, K. D., (2014), Mrs.Tsenhor: Female entrepreneur in ancient Egypt , American university in Cairo press.

Leitz, Ch., (1994), Tagewählerei,Das Büsh HAt nHH pHwy Dt und verwandte Texte, ÄgAbh 55 , Wiesbaden.

Mahler, ED, (1911), Der festkrallender von Medinet-Habu, Ein Beitrag zu den Grundprinzipien des Altägyptischen Kalenders, ZÄS 48. 


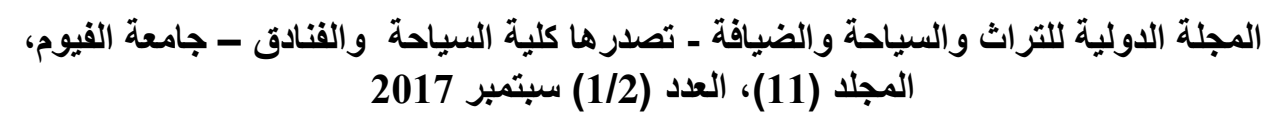

Meeks, D., (2001), "Demons" , The Oxford Encyclopedia of Ancient Egypt, Vol., I , New York.

Panagiotakopulu, E., (2004), " Pharonic Egypt and the origins of plague ", Journal of Biogeography, V.31.

Pinch, G.,( 1994), Magic in Ancient Egypt, London.

Raven, M., J., (1997), Charms for Protection during the Epagomenal Days, EMI, Essays on Ancient Egypt in Honour of Herman Te Velde, Groningen .

Ritner, R., K., (1993), The Mechanics of Ancient Egyptian Magical Practice, SAOC 54, Chicago.

Stricker, H., (1948), Spreuken Tot Beveiliging Gedurende de Schrikkeldagen Naar Pap. I 346, OMRO, 29.

Szpakowska, K., (2009),Demons in Ancient Egypt, Religion Compass 3/5 ,Swansea University.

Traut, E., B., (1988), " Der Menschliche Körper Eine Gliederpuppe" ZÄS 115 .

White, M., (1970), Ancient Egypt and its culture , New York.

\begin{abstract}
The five epagomenal days are a special period for the Egyptians. This period of transition is of a contradictory nature; it carries both good and evil, where the celebrations are held and the massacres are held. These days, fear has been born in the old Egyptian from the end of the year. At the beginning of these days, fear reigns and terrifies until it ends in peace and shows the dawn of the new year. Objectives: The research aims at uncovering the dangers of the five epagomenal days of ancient Egypt until the end of the Greco-Roman era, as well as an account of the means used by the ancient Egyptian to escape these dangers according to ancient Egyptian sources and beliefs.
\end{abstract}

Key Words: Five epagomenal days- Risks - Survival Ways - Messengers of Sakhmat - Khatio, Oshabti - Magical Amulets. 